\title{
We've discovered that projection across conjunction is asymmetric (and it is!)
}

\author{
Matthew Mandelkern ${ }^{1}$ (1) Jérémy Zehr ${ }^{2} \cdot$ Jacopo Romoli $^{3} \cdot$ Florian Schwarz $^{2}$
}

Published online: 27 August 2019

(C) The Author(s) 2019

\begin{abstract}
Is the mechanism behind presupposition projection and filtering fundamentally asymmetric or symmetric? This is a foundational question for the theory of presupposition which has been at the centre of attention in recent literature (Schlenker in Theor Linguist 38(3):287-316, 2008b. https://doi.org/10.1515/THLI.2008.021, Semant Pragmat 2(3):1-78, 2009. https://doi.org/10.3765/sp.2.3; Rothschild in Semant Pragmat 4(3):1-43, 2011/2015. https://doi.org/10.3765/sp.4.3 a.o.). It also bears on broader issues concerning the source of asymmetries observed in natural language: are these simply rooted in superficial asymmetries of language use (language use happens in time, which we experience as fundamentally asymmetric); or are they, at least in part, directly encoded in linguistic knowledge and representations? In this paper we aim to make progress on these questions by exploring presupposition projection across conjunction, which has traditionally been taken as a central piece of evidence that presupposition filtering is asymmetric in general. As a number of authors have recently pointed out, however, the evidence which has typically been used to support this conclusion is muddied by independent issues concerning redundancy; additional concerns have to do with the possibility of local accommodation. We report on a series of experiments, building on previous work by Chemla and Schlenker (Nat Lang Semant 20(2):177-226, 2012. https://doi.org/10.1007/s11050-012-9080-7) and Schwarz (in:
\end{abstract} Schwarz (ed) Experimental perspectives on presuppositions, Springer, Cham, 2015), using inference and acceptability tasks, which aim to control for both of these potential

We gratefully acknowledge audiences in Genoa, Utrecht, Göttingen, San Diego, Sydney, Milan, Frankfurt, Cornell, at the 30th CUNY, and at SALT 27; RA support from Nikhil Lakhani and Carissa Redfield; valuable discussion with an anonymous referee for this journal, Pranav Anand, Gennaro Chierchia, Alexandre Cremers, Daniel Rothschild, Philippe Schlenker, Robert Stalnaker, and Yoad Winter; and financial support from NSF-Grant BCS-1349009 to Florian Schwarz.

$\bowtie \quad$ Matthew Mandelkern

matthew.mandelkern@gmail.com; matthew.mandelkern@all-souls.ox.ac.uk

$1 \quad$ All Souls College, Oxford, UK

2 University of Pennsylvania, Philadelphia, USA

3 Ulster University, Belfast, UK 
confounds. In our results, we find strong evidence for left-to-right filtering across conjunctions, but no evidence for right-to-left filtering - even when right-to-left filtering would, if available, rescue an otherwise unacceptable sentence. These results suggest that presupposition filtering across conjunction is asymmetric, contra suggestions in the recent literature (Schlenker in Theor Linguist 34(3):157-212, 2008a. https://doi. org/10.1515/THLI.2008.013, 2009 a.o.), and pave the way for the investigation of further questions about the nature of this asymmetry and presupposition projection more generally. Our results also have broader implications for the study of presupposition: we find important differences in the verdicts of acceptability versus inference tasks in testing for projected content, which has both methodological ramifications for the question of how to distinguish presupposed content, and theoretical repercussions for understanding the nature of projection and presuppositions more generally.

Keywords Presupposition projection · Presupposition filtering · Asymmetry · Conjunction $\cdot$ Semantics-pragmatics interface $\cdot$ Experimental linguistics

\section{Introduction}

Is the mechanism behind presupposition projection and filtering fundamentally asymmetric or symmetric? That is, when processing presuppositions and determining whether they project, can we take into account only material that precedes a presupposition trigger, or can we also access material that follows the trigger (and, if so, must we do so)? This is a foundational question for the theory of presupposition which has been at the center of attention in recent literature and also bears on broader issues concerning the sources of asymmetries observed in natural language: are these rooted in superficial asymmetries of language use (since language use unfolds in time, which we experience as fundamentally asymmetric) or are they directly referenced in linguistic knowledge and representations? ${ }^{1}$

In this paper we aim to make progress on these questions by exploring presupposition projection and filtering across conjunction. The case of conjunction has traditionally been taken as a central piece of evidence that presupposition filtering is asymmetric in general: that is, that presuppositions can be filtered by material to their left, but not by material to their right. Recent work has argued, however that the evidence based on intuitions is much less clear than commonly assumed once we take into account independent issues of redundancy (Schlenker 2009; Rothschild 2008, 2011/2015; Chemla and Schlenker 2012). In addition, intuitions about the role of order in filtering across conjunction are muddied by the possibility of local accommodation. The question of the role of order for filtering in conjunction thus remains open.

\footnotetext{
1 See Schlenker (2008a, 2009), Fox (2008), Schwarz (2015), Chemla and Schlenker (2012) and Mandelkern and Romoli (2017) for discussion. We will use 'left-to-right' or 'right-to-left' to describe the potential order effects without making a commitment as to whether the relevant order is linear or hierarchical (since these coincide in the case of conjunction, it makes no difference for our purposes). For further discussion, see Romoli and Mandelkern (2018), Chung (2017), Chierchia (2009), Ingason (2016) and George (2008); see also the conclusion below.
} 
We report on a series of experiments which aim to address this question using inference and acceptability tasks which control for redundancy and local accommodation, building on previous work by Chemla and Schlenker (2012) and Schwarz (2015). We find strong evidence for left-to-right filtering across conjunctions, but no evidence for right-to-left filtering, even when it would rescue an otherwise unacceptable sentence. We argue that these results suggest that presupposition filtering across conjunction is asymmetric: material in the left conjunct can filter presuppositions in the right conjunct, but not vice versa.

The rest of the paper is organised as follows. After setting the stage, we report the individual experiments in turn. We then turn to a general discussion of the upshot of the overall experimental results; methodological implications of those results; comparisons to past work in the literature; and avenues for future research.

\section{Background}

Presuppositions are contents associated with certain lexical items or constructions (triggers) which are typically felt to be backgrounded, and which display projection behaviour with two characteristic features. First, the inference to the presupposed content is generally licensed even when the trigger is embedded in a variety of entailment-canceling environments (Karttunen (1973)'s holes, Chierchia and McConnell-Ginet (1990)'s family of sentences), such as questions, antecedents of conditionals, or epistemic modals. Thus the inference from (1a) that Mary used to do yoga is also licensed when (1a) is embedded in the presupposition holes in the other variants in (1). This is by contrast to the inference that Mary is not doing yoga now, which is also licensed by (1a) but not by the other variants:
a. Mary stopped doing yoga.
b. If Mary stopped doing yoga, then Matthew will interview her for his story.
c. Did Mary stop doing yoga?
d. Mary might have stopped doing yoga.

Second, presuppositions characteristically fail to project-they are filtered, in Karttunen's terminology - when their content is entailed by the trigger's local context. We leave informal the notion of local context here; it can be spelled out in various ways, and our question-whether filtering is symmetric or asymmetric-of course bears directly on the question of how to characterize local contexts. ${ }^{2}$ We take for granted certain basic cases, however: for instance, that the local context of the consequent of a conditional entails its antecedent; that the local context for a right conjunct entails the left conjunct; and that the local context for a right disjunct entails the negation of the left disjunct. Thus none of the complex sentences in (2) presupposes that Mary used to do yoga:

\footnotetext{
2 See Karttunen (1974), Stalnaker (1974) and Heim (1983) for classic treatments, and Schlenker (2009) for important recent work. For accounts not based on the notion of local contexts see Schlenker (2008b), Fox (2008), Chemla (2008) and George (2008) among others.
} 
(2) a. If Mary used to do yoga, then she stopped doing yoga.

b. Mary never used to do yoga, or else she stopped doing yoga.

c. Mary used to do yoga, and she stopped doing yoga.

In some cases, this is obvious: e.g. (2a) and (2b) clearly do not license the inference that Mary used to do yoga. In other cases, such as (2c), things are more subtle, since (2c) does license the inference that Mary used to do yoga. But this inference does not have the status of a presupposition. We can see by looking at the behavior of (2c) when embedded in a presupposition hole, as in (3a): the inference that Mary used to do yoga is no longer supported by this sentence, contrary to what we would expect if it were a presupposition of the antecedent, which is (2c). This contrasts with the minimal variant in (3b), where the left conjunct is unrelated to the presupposition of the right conjunt, and where the inference that Mary used to do yoga does project.

a. If Mary used to do yoga and she stopped doing yoga, then Matthew will interview her for his story.

b. If Mary lives in Boston and she stopped doing yoga, then Matthew will interview her for his story.

These examples show that material to the left of a given presupposition trigger can be taken into account in filtering its presupposition. The question we are concerned with in this paper is whether the material to the right can also be taken into account. We will focus on conjunctions, so our question in particular is: can right conjuncts play a role in filtering the presuppositions of left conjuncts, or only vice versa? The traditional assumption in the literature has been that filtering across conjunction is exclusively left-to-right, based on contrasts like that between (4a) (which has a presupposition trigger in a right conjunct, with the presupposition filtered by the left conjunct) versus (4b) (which reverses this order) (Stalnaker 1974; Karttunen 1974; Heim 1983 among others):

a. Mary used to do yoga and she stopped doing yoga.

b. \# Mary stopped doing yoga and she used to do yoga.

But, as Karttunen (1973), Chemla and Schlenker (2012), Rothschild (2008, 2011/2015) a.o. discuss, it is not entirely clear what such contrasts show. (4b) is certainly marked, and one explanation for this could be that presuppositions must be filtered by material which appears to the left of their trigger, as in (4a). The presupposition in (4b) would consequently project and be the source of the sentence's markedness. But this explanation does not suffice, since presupposition triggers can appear, to a certain extent, in contexts that do not support them, in which case the presupposition is commonly accommodated, as when (5) is asserted out of the blue: ${ }^{3}$

\footnotetext{
${ }_{3}^{3}$ For the notion of accommodation see von Fintel (2008) and references therein.
} 


\section{(5) Mary stopped doing yoga.}

The infelicity of (4b), and its contrast with (4a), thus is likely to (at least in part) have an explanation in terms of independent factors. And, indeed, an independent explanation is ready at hand. (4b) has the structure $\left\ulcorner S_{p}\right.$ and $\left.p\right\urcorner$ (where $S_{p}$ is a sentence which presupposes $p$ ). There is something marked about roughly parallel cases that don't involve presuppositions: sentences of the form $\left\ulcorner p^{+}\right.$and $\left.p\right\urcorner$ (where $p^{+}$is a sentence which entails, but is not entailed by, $p$ ), as we can see in the contrast between (6a) and (6b):

a. John is a college student, and he is majoring in English.

b. \# John is majoring in English, and he is a college student.

Theories of redundancy (following Stalnaker 1978) capture this contrast based on the idea that we generally want our contributions to conversation to incrementally augment the common information as they proceed (see Schlenker 2008a, 2009; Katzir and Singh 2013; Mayr and Romoli 2016 among others). In the case of conjunction, this requirement is applied to each conjunct separately, such that the second conjunct has to add information relative to the first, which accounts for the contrast above: sentences of the form $\left\ulcorner p\right.$ and $\left.p^{+}\right\urcorner$are compatible with this requirement, since the right conjunct adds information to the first; sentences of the form $\ulcorner p+$ and $p\urcorner$ are not, since the second conjunct does not add anything beyond the first. Assuming that $S_{p}$ entails $p$-or that the constraint invoked here otherwise takes into consideration presupposed content in some manner-the same explanation extends to cases of the form $\left\ulcorner S_{p}\right.$ and $\left.p\right\urcorner$, such as (4b) above. Thus it is not clear that the relative infelicity of (4b) as compared with (4a) tells us anything about presupposition projection in particular, as opposed to something more general about redundancy.

To circumvent issues about redundancy, we can modify our test paradigm slightly, following Rothschild (2008, 2011/2015) and Chemla and Schlenker (2012). So far, we have contrasted sentences of the form $\left\ulcorner p\right.$ and $\left.S_{p}\right\urcorner$ versus $\left\ulcorner S_{p}\right.$ and $\left.p\right\urcorner$. Instead, however, we can contrast sentences of the form $\left\ulcorner p^{+}\right.$and $\left.S_{p}\right\urcorner$ with sentences of the form $\left\ulcorner S_{p}\right.$ and $\left.p^{+}\right\urcorner$, as in (7):

a. Mary used to do Jivamukti yoga and she stopped doing yoga.

b. Mary stopped doing yoga and she used to do Jivamukti yoga.

This paradigm circumvents issues about redundancy, because $p^{+}$adds something beyond $S_{p}$, and likewise $S_{p}$ adds something beyond $p^{+}$: neither entails the other. Thus, on the basis of issues about redundancy alone, there should be nothing wrong with conjunctions of $p^{+}$and $S_{p}$ in either order. And indeed, we do not find the same contrast in felicity in (7) as we did in (4a) versus (4b) above: if there is a contrast in (7) at all, it is far less clear than in (4a) versus (4b), suggesting that the latter contrast was at least in part driven by redundancy, and not presupposition projection.

Does this show, then, that presupposition projection across conjunction is in fact symmetric? Not at all. It simply controls for one orthogonal issue affecting felicity judgments. The relative felicity of (7b) could be due to symmetric filtering. But it could also result from felicitous accommodation of the presupposition. To determine whether presupposition projection across conjunctions is symmetric, we need to push 
further by testing whether presuppositions project equally out of constructions with the form of (7a) $\left(\left\ulcorner p^{+}\right.\right.$and $\left.S_{p}\right\urcorner$ ) and (7b) $\left(\left\ulcorner S_{p}\right.\right.$ and $\left.\left.p^{+}\right\urcorner\right)$. This question cannot be answered by looking at simple conjunctions, since the inference to the presupposition is licensed for both orders just given the logical nature of conjunction and the potential for accommodation. Instead, we again need to embed these sentences further under presupposition holes, e.g. in the antecedents of conditionals as in (8), and explore what projects (cf. Rothschild 2008, 2011/2015):

a. If Mary used to do Jivamukti yoga and she stopped doing yoga, then Matthew will interview her for his story.

b. If Mary stopped doing yoga and she used to do Jivamukti yoga, then Matthew will interview her for his story.

The crucial question now is whether (8b), which has the form $\left\ulcorner\right.$ If $S_{p}$ and $p^{+}$, then $\left.q\right\urcorner$, licenses the inference that Mary used to do yoga. Given the uncontroversial existence of left-to-right filtering, (8a) is expected to not support the inference, in line with what we already observed for (3a). If right-to-left filtering is possible, then ( $8 b$ ) should also not support this inference-or at least do so less than controls with the form $\left\ulcorner\right.$ If $S_{p}$, then $q\urcorner$. If, on the contrary, there is no right-to-left filtering, then the presupposition from the first conjunct, that Mary used to do yoga, should project to the same degree as in a presuppositional control. Note that order-based asymmetries here could be categorical or gradient in nature, i.e., right-to-left filtering could turn out to not exist at all, or merely be less readily available than left-to-right filtering. Teasing these possibilities apart empirically is a tall order, but doing so has substantial consequences for weighing various theoretical options, which we will turn to in the general discussion of the experimental results.

In evaluating the key data points, there is a final confound which we must be careful to control for: namely, the possibility of local accommodation. ${ }^{4}$ In certain circumstances, presuppositions fail to project; e.g. (9) has a coherent, if slightly marked, reading, where the incompatibility of the last part of the sentence with a globally interpreted presupposition forces a non-presuppositional reading of the first part of the sentence:

(9) Mary didn't stop doing yoga—she never did yoga to begin with!

Local accommodation in general encompasses cases in which presuppositions triggered in entailment-canceling environments that generally project presuppositions, like negation and antecedents of conditionals, do not wind up as inferences supported by the utterance as a whole. In assessing the filtering properties of complex sentences, it is thus crucial to distinguish failure to project due to local accommodation from failure to project due to filtering, either left-to-right or right-to-left. As we discuss below, our experimental designs accomplish this by including a simple presuppositional control condition where failure to project can only be due to local accommodation, thus providing a baseline relative to which any separate effects of filtering can be assessed.

\footnotetext{
4 A phenomenon sometimes also referred to as presupposition suspension. 'Local accommodation' comes from Heim (1983), where it is used to talk about a particular model of the phenomenon in which presuppositions fail to project in cases we expect them to; following much of the subsequent literature, we use it here as a name for the phenomenon without making a commitment to any particular model of the phenomenon.
} 
In sum, our question is whether, after controlling for issues of redundancy (by strengthening the non-presuppositional conjunct) and for local accommodation (by comparing with a simple presuppositional control), we find a difference in the availability of projection out of the antecedents of conditionals of the form $\left\ulcorner\right.$ If $p^{+}$and $S_{p}$, then $q\urcorner$ (like (8a)) and $\left\ulcorner\right.$ If $S_{p}$ and $p^{+}$, then $\left.q\right\urcorner$ (like (8b)), respectively. If so, this would support an asymmetric perspective on which left-to-right filtering is more available than right-to-left filtering; if not, it would support a symmetric approach. Further, if we find lower projection for $\left\ulcorner\right.$ If $S_{p}$ and $p^{+}$, then $\left.\mathrm{q}\right\urcorner$ versus a simple presuppositional control $\left\ulcorner\right.$ If $S_{p}$, then $\left.q\right\urcorner$, it will suggest that right-to-left filtering is possible (even if it turns out to be less accessible than left-to-right filtering); by contrast, if we do not, it provides at least pro tanto evidence that right-to-left filtering is not possible at all.

One option at this juncture is to consult our own intuitions, and there is some precedent for this in the literature; Rothschild (2008, 2011/2015), for instance, reports that in his judgment, there is no projection from either sentences of the form (8a) or those of the form (8b). But, as Rothschild (2011/2015) himself notes, intuitions here are quite subtle- too subtle, it seems to us, to settle without a more systematic empirical assessment, using an experimental approach. In light of this, we conducted three experiments collecting speaker judgments with the aim of ascertaining whether, and to what extent, there is projection from sentences with these forms. The first two experiments use an inference task, and yield results that confirm the existence of asymmetries, but also give rise to new questions about what exactly is being measured. The third experiment uses acceptability judgments, which provide further evidence for asymmetry - even in contexts where right-to-left filtering would rescue an otherwise infelicitous assertion - and also helps us home in on the notion of projection relevant to the theory of presupposition.

Ours is not the first experimental work to explore (a)symmetry in projection. The main precedents in this respect are reported in Chemla and Schlenker (2012) and Schwarz (2015). We will discuss those precedents in more detail in Sect. 6.3 below. But it is worth highlighting some key differences between these previous studies and ours right away. First, those studies do not look at conjunction, which is a case of central importance in this debate. Second, those studies do not use the present paradigm for controlling for issues related to redundancy. Finally, they use a different set of presupposition triggers (additive particles) that arguably have idiosyncratic projection properties, as we discuss below, which in turn invites caution in generalizing from their behavior.

\section{Experiment 1}

\subsection{Design}

The first two experiments explored our central question using an inference task. Participants read a sentence and were asked whether they would draw a given inference from that sentence. In the critical trials, the sentence had the form of a conditional whose antecedent contained a conjunction. One of the conjuncts contained a presupposition trigger, and the other conjunct entailed the presupposition; this entailment 
was always asymmetric, so as to control for issues about redundancy. We manipulated whether the presupposition trigger appeared in the left or in the right conjunct of that conjunction. (10) illustrates how these elements were phrased and displayed. Participants had to indicate whether they would conclude that the proposition introduced by the presupposition trigger (here, that Mary used to do yoga) holds by pressing ' $F$ ' or ' $\mathrm{J}$ '.

(10) a. If Mary stopped doing yoga and she used to do Jivamukti yoga, then Matthew will interview her for his story.

b. This leads me to conclude

c. Mary used to do yoga.

$\begin{array}{cc}\mathbf{F} & \mathbf{J} \\ \text { Yes } & \text { No }\end{array}$

The rationale, following the logic laid out above for (3a) and (8), is that if the presupposition introduced by the trigger projects, participants should reason that their (fictional) interlocutor took its truth for granted, and correspondingly endorse the inference that it holds. On the other hand, if it fails to project (due to filtering or local accommodation), its truth should be taken as hypothetical since the presupposition would only contribute to the antecedent of the conditional, rendering the inference as unwarranted. By manipulating conjunct order (Conj-Ps-First as in (8a) vs. Conj-PsSecond as in (8b)), we tested for (a-)symmetry in filtering. If only preceding material can filter the presupposition of a given trigger, filtering will only be available when the trigger appears in the second conjunct. By contrast, if both preceding and subsequent material can filter presuppositions, then we would expect filtering to be available in both conjunct orders. As discussed above, this could still yield a gradient (a)symmetry, if right-to-left filtering turned out to be available in principle, but to a lesser extent than left-to-right filtering, or it could point towards categorical symmetry.

Given the caveat that, in principle, lack of projection can either be due to filtering or to local accommodation, absolute inference rates do not suffice to establish the presence or absence of filtering. To control for this, our design also included variants of test items as in (11), with a simple, non-conjunctive, presuppositional antecedent.

\section{(11) Simple Ps:}

If Mary stopped doing yoga, then Matthew will interview her for his story.

Controls like (11) provide a baseline for projection. The only thing that could prevent projection from a sentence like (11) would be local accommodation. Therefore rates of projection out of sentences like this one will provide a baseline for projection in the task. To the extent that the critical variants with conjunctive antecedents exhibit the use of an additional mechanism to prevent projection, namely filtering, this should be reflected in relatively lower inference endorsement rates than in the simple control variants, where the only mechanism that could prevent projection is local accommodation. 
At the other extreme, we also included a baseline for non-projection in the form of conditionals with simple non-presuppositional (Simple-No-Ps) antecedents like (12). This establishes how likely participants were to infer that content introduced in the antecedent would hold, even in the absence of presuppositional expressions.

\section{Simple-No-Ps:}

If Mary used to do yoga, then Matthew will interview her for his story.

All existing accounts predict that filtering is obligatory whenever possible, and thus that if filtering is asymmetric, then there will be no difference in inference rates between Conj-Ps-Second and Simple-No-Ps. ${ }^{5}$

\subsection{Materials, procedure, and participants}

We created 32 critical items which came in four variants corresponding to the four conditions described above. (13) provides a schematic illustration. The question associated with these items was always whether it would lead participants to conclude $p$.
a. If $S_{p}$ and $p^{+}$, then $q$.
b. If $p^{+}$and $S_{p}$, then $q$.
c. If $S_{p}$, then $q$.
d. If $p$, then $q$.
Conj-Ps-First (8a)
Conj-Ps-Second (8b)
Simple-Ps (11)
Simple-No-Ps (12)

Four counter-balanced lists of items were created, so that participants saw eight repetitions in each of these four conditions, while only seeing each item in one version. We used four different presupposition triggers to create the items: aware (that), happy (that), stop, and continue. As a result, each participant saw two different trials in each condition per trigger. We also included 48 filler items. 12 of them were structurally identical to (13a) and (13b) but asked participants whether they inferred $p^{+}$ (rather than $p$ ); 12 were structurally identical to (13c) but asked participants whether they inferred $q .16$ filler items were structurally parallel to (13a) and (13b) but had non-presuppositional embedding expressions (hope (that), doubt (that), try (to), plan (to)) and asked participants whether they inferred $p, p^{+}$or $q$. Finally, 8 filler items consisted of non-conditional, conjunctive sentences of various forms and asked participants whether they inferred one of the conjuncts. See the Appendix for a list of all items. $^{6}$

\footnotetext{
5 Though in DRT accounts, this is just a stipulation (namely, that we always find local "antecedents" for presuppositions whenever possible), and so is in a sense separable from the rest of the theory's commitments.

${ }^{6}$ One might wonder whether the fact that in items like (10), in which the stronger clause $p^{+}$is obtained from the weaker one $p$ by adding a modifier to the noun (e.g. 'Jivamukti yoga' vs. 'yoga') could have an effect which interacts with presupposition filtering, possibly in an asymmetric way. In particular, it could be that the unmodified noun occurring after the modified noun is interpreted as a 'lazy' way to refer back to the modified version. While we cannot exclude that there could be some effect along these lines, we note that only a small share (about a quarter) of the items involved this configuration and it is therefore very unlikely that this could drive any contrast we find in the results below. Furthermore, a visual inspection of by-item means revealed no systematic differences in effects for items that have this property and ones that don't. Finally, note that the design of Experiment 2 aims to control for such effects by including non-presuppositional controls. Thanks to an anonymous reviewer for discussion on this point.
} 
Participants started the experiment with two practice trials where the separate elements in the display were revealed step by step, with tool-tips explaining the nature of the task: they were invited to imagine that a given sentence (corresponding to (10a)) was produced by a fictional interlocutor and to indicate whether they would conclude that a relevant statement (corresponding to (10c)) held based on what their interlocutor said. The practice trials were designed as clear cases of endorsement and non-endorsement of the conclusion (using (non-)entailments of an unembedded conjunction and disjunction respectively), and feedback on their responses provided through tool-tips reinforced the notion that the fictional interlocutor should be deemed reliable. An archived version of the experiment can be accessed online at http://spellout.net/ ibexexps/SchwarzLabArchive/IncrSymExp1/experiment.html?Home=T.

We recruited 50 native English speakers online from the participant pool of Prolific.ac. They were rewarded $£ 1.80$ for their participation and took an average of 16 minutes to complete the task. They were distributed in four groups, following a latinsquare distribution of the four conditions over the 32 items, so that each item appeared in each condition across participants in the data we collected.

\subsection{Results}

The graph in Fig. 1 shows the mean inference endorsement rates in each of the four critical conditions (see Appendix for detailed results on filler conditions). The error bars indicate standard errors of the mean. ${ }^{7}$ The Simple-No-Ps and Simple-Ps conditions serve as baseline and ceiling comparisons respectively. As expected, the inference endorsement rate is low for the former and high for the latter, though there is some noise, presumably due to the relative complexity of the task. (In addition, the rates for Simple-Ps may be lowered due to a possibility of local accommodation.) Crucially, the critical condition with the trigger in the first conjunct (Conj-Ps-First) is on par with Simple-Ps, while the inference endorsement rate is lower when the trigger is in the second conjunct (Conj-Ps-Second), though—somewhat unexpectedly-higher than in the baseline Simple-No-Ps condition.

In order to assess these effects statistically, we conducted analyses using mixedeffect logistic regression models (lme 4 version 1.1-13; $R$ version 3.3.3) predicting the observation of a 'Yes' answer as a function of Condition (Conj-Ps-First vs. Conj-PsSecond vs. Simple-Ps vs. Simple-No-Ps). The models included random intercepts for participants and items (but no random slopes, due to failures to converge). Given that accuracy on basic fillers (the conjunctive ones, see Fillers (d) and (e) in Appendix) was close to ceiling throughout, we didn't remove any data points for purposes of analyses. We found significant differences between every pair of conditions (all $p$ 's $<0.001$ ) except between Conj-Ps-First and Simple-Ps $(p=0.315)$. Additional details on the statistical results are provided in the Appendix.

\footnotetext{
7 Note that these do not correspond directly to the parameters in the statistical models used to analyze the data. (This goes for the result graphs for Experiments 2 and 3 as well.)
} 
Fig. 1 Mean inference rates of $p$ per condition in Experiment 1

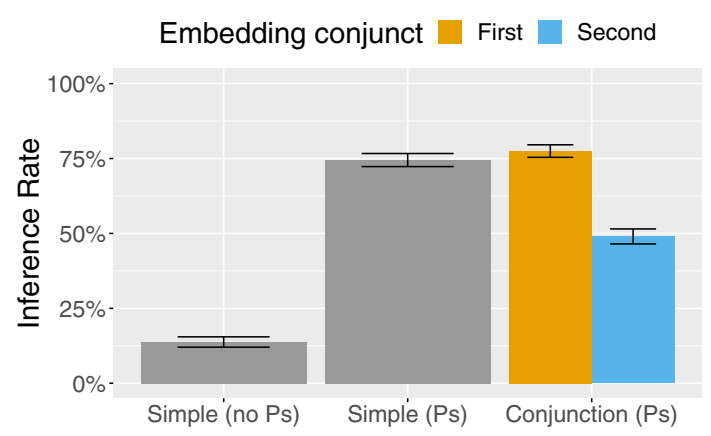

\subsection{Discussion}

With regard to our central question of (a-)symmetry, we found significantly lower rates of inference endorsement in Conj-Ps-Second than in the projection baseline Simple-Ps, and we found a significant effect of conjunct order on inference endorsement rates, with higher rates in Conj-Ps-First than in Conj-Ps-Second. Together, these findings provide evidence, first, for the (uncontroversial) claim that a left-to-right filtering mechanism is available, since left-to-right filtering should lead to fewer inference endorsements in Conj-Ps-Second than in Simple-Ps. Second, they provide evidence for the claim that left-to-right filtering is more available than right-to-left filtering, directly confirming a gradient asymmetry, as there are relatively higher rates of endorsement in Conj-PsFirst than in Conj-Ps-Second. Moreover, the lack of a significant difference between Conj-Ps-First and the projection baseline provided by Simple-Ps (with numerically higher inference endorsement rates in the former) suggests that there is no effect of right-to-left filtering in our task. This suggests, prima facie, that filtering is not only more available in Conj-Ps-Second than in Conj-Ps-First, but that it is possibly not available at all in Conj-Ps-First, in line with a categorical asymmetry where filtering is exclusively left-to-right.

A surprising aspect of our results is that while the inference endorsement rates for Conj-Ps-Second were significantly lower than for Conj-Ps-First, they also were significantly higher than in the non-projection baseline control provided by Simple-No-Ps. Given that the standard theoretical assumption is that filtering, when available, always takes place, finding any amount of projection in a configuration where left-to-right filtering is clearly available is unexpected. While we are not in a position to fully explain this aspect of our data here, we note that there are potential factors that could bear on this independently of the nature of the projection mechanism. The most obvious possibility is that participants failed to perceive the entailment relationship between the non-presuppositional conjunct and the presupposition. ${ }^{8}$ In that case, filtering would not be expected regardless of order. If variation in entailment comprehension is solely responsible for the effect, this finding would be compatible with standard assumptions after all. Of course there may be other factors at play as well. Regardless of how

\footnotetext{
8 The manipulations in our materials to create the entailment relationship were varied, and included the use of lexical hymonymy (coffee vs. espresso), compounds (toys vs. toy cars), and world knowledge (going to France vs. going to Paris). See the Appendix for the complete list of the items.
} 
this surprising projection is ultimately explained, we will argue that our third experiment, which looks at acceptability judgments rather than inference tasks, succeeds at abstracting away from whatever factors other than projection may increase inference endorsement rates in an inference task like this one, and thus provides a more direct assessment of the relevant theoretical notion of projection.

Returning to our main question, while our results are in line with asymmetric accounts of filtering, alternative explanations of the observed contrast in inference endorsement based on conjunct order should be considered as well. A first potential alternate explanation is that two of the triggers employed (aware and happy) were in principle open to syntactic ambiguity, so that the second conjunct in the Conj-Ps-First versions could potentially be interpreted in the scope of the trigger (i.e. they could be interpreted as $\left\ulcorner\ldots\right.$ aware/happy that $\left[p\right.$ and $\left.\left.p^{+}\right]\right\urcorner$, leading to projection of $p^{+}$). But two points speak against this being the sole driving factor in our results, if it has an effect at all: first, the interpretation in question seems intuitively dispreferred, especially with a that preceding the first conjunct but not the second, a format which we intentionally adopted to at least partly counter this worry; e.g. 'If Douglas is happy that Sharon is moving to Africa and she is moving to Kenya, then he will help her with the move' doesn't seem to have a natural interpretation on which Douglas is happy that Sharon is moving to Kenya. Second, if this were the only factor responsible for the observed asymmetry, the effect of order should not have been present for the other two triggers (stop and continue), whose complement takes a verb ending in -ing, with no option of an overt complementizer. But as can be seen in the graph showing individual results by trigger in the Appendix, the asymmetry seems to be uniformly present across all four triggers, so this worry is not substantiated by our data.

A second concern, however, is more serious. The format of the critical versions of our sentences differs from the controls in that only the former had conjunctions in the antecedent of the conditional, which leaves room for independent effects based on conjunction that are unrelated to the presuppositions at play. For example, the second conjunct could have received a parenthetical interpretation taking it outside the scope of the conditional, as illustrated in (14).

(14) a. If Mary stopped doing yoga—and she used to do Jivamukti yoga—, then Matthew will interview her for his story.

b. If Mary used to do Jivamukti yoga — and she stopped doing yoga-, then Matthew will interview her for his story.

(14a) sounds like a plausible utterance to us, with the material enclosed in the dashes interpreted outside the scope of the conditional antecedent: parentheticals introduce information as backgrounded, and the parenthetical conjunct (that Mary used to do Jivamukti yoga, schematically $p^{+}$) in (14a) can naturally be interpreted as adding background details (outside of the conditional) to the information in the antecedent, details that naturally can be seen as reinforcing the relevance of the conditional, and which supports the antecedent's presupposition. In contrast, the parenthetical conjunct in (14b) (that Mary stopped doing yoga, schematically $S_{p}$ ) does not lend itself to being seen as adding details to the first conjunct in a parallel manner. Likely due to the lack of such an interpretation, this sentence seems less felicitous to us under a parenthetical 
construal. Moreover, it's clear that no parenthetical interpretation of the first conjunct of the antecedent is possible. So a parenthetical construal is only available in our Conj-Ps-First sentences. And this construal would favor endorsing the inference that $p$ holds. Given the lack of availability of such a construal for the Conj-Ps-Second sentences, this could be responsible for the contrast in inference endorsement rates based on conjunct order in our data. If this were so, then this contrast would not necessarily show that there is an asymmetry in projection, with left-to-right filtering being more available than right-to-left filtering; the apparent contrast could rather be the result of the combination of at least some right-to-left filtering, together with at least some inference endorsements in the Conj-Ps-First condition being due to parenthetical interpretations. This worry is further corroborated by an inspection of the filler items (see Appendix for detailed results): one set of fillers was entirely parallel to the experimental items but asked about $p^{+}$(the other conjunct), and yields an order effect as well, suggesting that even the non-presupposed $p^{+}$is endorsed some of the time, and more so when the presupposition trigger conjunct comes first. A second set of fillers used conjunctions with non-presuppositional embedding verbs. While these were not rigorously controlled in relevant ways, and the data was more limited in that only some of these asked whether $p$ (as opposed to $p^{+}$or $q$ ) could be inferred, they also yielded at least suggestive evidence that there could be some asymmetries in endorsements of $p$ even in the absence of a presupposition trigger.

In order to control for these potential alternative explanations in terms independent of the properties of presupposition projection, we conducted a second experiment. The key change was for our critical items to systematically include control variations where the presuppositional expressions were replaced by structurally similar nonpresuppositional ones, while leaving the conjunctions untouched otherwise.

\section{Experiment 2}

\subsection{Design}

Experiment 2 was a simple variation of Experiment 1, in that the control variations of the critical items now comprised versions where the presuppositional verbs were replaced by non-presuppositional ones, yielding non-presuppositional sentences with either conjunct order Conj-No-Ps-First ( $\left\ulcorner\right.$ If $S_{(p)}$ and $p^{+}$, then $\left.q\right\urcorner$, where $S_{(p)}$ is a sentence which embeds but does not presuppose $p$ ) and Conj-No-Ps-Second ( $\left\ulcorner\right.$ If $p^{+}$and $S_{(p)}$, then $\left.\left.q\right\urcorner\right)$. This manipulation allowed us to control for potential conjunct-order effects independent of the presuppositional component, such as the one considered above. Since the new control items didn't contain presupposition triggers, the inference rates observed in these conditions provide a baseline for any effects independent of presupposition filtering. Thus, if there are general order effects present in both presuppositional and non-presuppositional sentences, any additional presupposition-based asymmetries should be reflected in even greater order effects for the presuppositional variants. In other words, the asymmetry hypothesis that left-to-right is more available than right-to-left filtering predicts a statistical interaction between Embedding Type (Ps vs. No-Ps) and Order (First vs. Second). 


\subsection{Materials and participants}

The materials from Experiment 1 were adapted slightly to allow for minimal variations including the new controls, building on the format of non-presuppositional filler items from Experiment 1, but implemented more systematically and as a within-item variation. Each presupposition trigger was paired with a non-presuppositional expression as follows to maximize plausibility in all embedding verb variants while leaving the remainder of the sentences unchanged: happy (that)/hope (that), aware (that)/sure (that), stop/frown on ( $V$-ing), continuelenjoy ( $V$-ing). (15) lists the resulting 4 conditions. (16) illustrates the Conj-No-Ps-Second version of our running example (8).

a. If $S_{p}$ and $p^{+}$, then $q$.

Conj-Ps-First

b. If $p^{+}$and $S_{p}$, then $q$.

Conj-Ps-Second

c. If $S_{(p)}$ and $p^{+}$, then $q$.

Conj-No-Ps-First

d. If $p^{+}$and $S_{(p)}$, then $q$.

Conj-No-Ps-Second

(16) If Mary used to do Jivamukti yoga and she frowns on doing yoga, then Matthew will interview her for his story.

As before, 32 critical items in four versions were counter-balanced across four lists, so that each participant would see 8 repetitions of each critical condition. A full list of critical stimuli is provided in the Appendix. In addition, there were 32 filler items taken directly from Experiment 1, namely 16 presuppositional fillers with complex antecedents where an inference based on the consequent or the non-embedding conjunct had to be assessed, as well as 8 presuppositional fillers with a simple antecedent (with an inference about the consequent), and 8 conjunctive fillers, 3 presuppositional, and 5 non-presuppositional (with varied inferences being assessed). See the Appendix for Experiment 1 for illustrations. Finally, 16 filler items were created in both Simple-Ps and Simple-No-Ps variations, so that each participant saw 8 repetitions of each. These were adapted from the lexical materials used for non-presuppositional fillers with complex antecedents from Experiment 1, and again provided a point of reference for baseline and ceiling in terms of supporting the critical inferences, while also controlling for local accommodation. An archived version of the experiment can be accessed online at http://spellout.net/ibexexps/SchwarzLabArchive/IncrSymExp2/ experiment.html?Home $=\mathrm{T}$.

We recruited 49 students (all self-reported native speakers of English) through the Psychology Subject Pool at the University of Pennsylvania, who took the experiment on a lab computer and received course credit for their participation. ${ }^{9}$

\subsection{Results}

The graph in Fig. 2 shows the mean inference rates in the baseline (grey) and critical (orange and blue) conditions. As before, the fillers with simple (non-conjunctive)

\footnotetext{
9 Note that the replication of the results from Experiment 1, detailed below, thus validates the paradigm across two populations.
} 
Fig. 2 Mean inference rates of $p$ per condition in Experiment 2

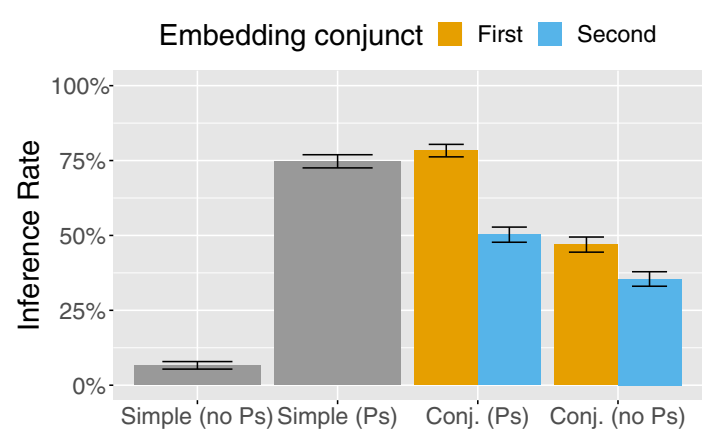

antecedents provide points of reference for floor and ceiling levels, and pattern as expected and virtually identically to Experiment 1 . The critical presuppositional conjunction conditions exhibit an order effect, with higher inference endorsement rates when the trigger appears in the first conjunct, parallel to that in Experiment 1 as well. The non-presuppositional conjunction controls also exhibit an order effect, although it seems to be weaker here. To assess these effects statistically, analyses parallel to those for Experiment 1 above were conducted. Accuracy was high throughout so no data were removed before analysis. Models predicting responses from the four critical conditions included two predictors, Embedding Type (Ps vs. No-Ps) and Order (First vs. Second) and their interaction, as well as random intercepts for participants and items, and as random slopes to the extent that it was possible to include them in terms of models converging while avoiding random effects correlations approaching 1 (see Appendix for details). Crucially, there was a significant interaction between the two factors, as well as significant main effects (all $p$ 's $<.001$; see Appendix for details). There also were corresponding significant simple effects of both predictors (at all levels) (all $p$ 's $<0.001$, except for non-presuppositional order effect, with $p<.01$; see Appendix for details). Additional models predicting responses from the test and baseline conditions (between-item) included one four-leveled predictor (Conj-Ps-First vs. Conj-Ps-Second vs. Simple-Ps vs. Simple-No-Ps), a random slope for participants and random intercepts for participants and items. They revealed that the contrast between Conj-Ps-First and Simple-Ps was not significant $(p=0.423)$ but the one between Conj-Ps-Second and Simple-No-Ps was $(p<0.001)$, replicating the pattern found in the main analysis for Experiment 1 . Given the intermediate level results for the non-presuppositional controls, we extended the same approach to these as well, which revealed that for both orders, they were significantly different from both Simple-Ps and Simple-No-Ps ( $p$ 's $<.001)$.

\subsection{Discussion}

As in Experiment 1, we found evidence for asymmetry in the form of a significant contrast between Conj-Ps-First and Conj-Ps-Second, replicating our web-based results there in a lab setting with college student subjects. However, the suspected confound of general order effects, independent of presuppositionality, was also substantiated to some extent, given the main effect of order and corresponding simple effects for 
both $P s$ and No-Ps. But crucially, we also find a significant interaction between Order and Embedding Type. This indicates that, while there is an order effect of the kind we hypothesized post hoc in Experiment 1 (perhaps due to parenthetical readings, perhaps due to some other mechanism), presuppositional variants are subject to an additional factor that further enhances the order effect. The most natural explanation of this is an asymmetry specific to presupposition filtering, with left-to-right filtering being more available than right-to-left filtering. ${ }^{10}$

Once again parallel to the findings of Experiment 1, inference rates were comparable in Conj-Ps-First and Simple-Ps. Taken at face-value, this could be seen as further substantiating the conclusion that there is no evidence for right-to-left filtering in the present paradigm. However, the finding of a general, presupposition independent order effect in the new data also opens up the possibility that right-to-left filtering does have a presence in the data, but its effect is hidden by other, non-presupposition-related inferences having to do with order effects (perhaps due to parenthetical readings), which could add an independent boost here. Thus, while the interaction effect between Order and Embedding Type clearly supports gradient asymmetry in projection from conjunction, the data from the first two experiments do not conclusively support categorical asymmetry.

An additional result is that we find further evidence for the somewhat surprising effect for Conj-Ps-Second observed above: even in this condition, where left-toright filtering would be expected to be operative, there is an increase in inference endorsements relative to baseline (Simple-No-Ps) and control (Conj-No-Ps-Second) conditions. As before, this could be due to failure of perceiving the relevant entailment relationship, but other, perhaps discourse-related factors, could be at play as well, so further work is required to assess this otherwise theoretically surprising finding more carefully.

Finally, another surprising result is that even non-presuppositional conjunctive variants yield increases in inference endorsement rates, relative to simple (nonconjunctive) non-presuppositional controls, and in both orders (and thus cannot be solely attributed to a parenthetical reading of the kind suggested above). This raises the question of what this should be attributed to. Possible explanations could allude to latent or gradient presuppositionality of (at least some) of our non-presuppositional predicates, or to the somewhat particular discourse structure induced by the general frame for our stimuli (with one conjunction containing an embedded clause, and the other entailing that embedded clause). Before jumping to conclusions, it is important to bear in mind that these effects could well be specific to the inference-task at hand, and it is by no means clear that endorsing an inference in this paradigm should automatically be seen as diagnosing the standard theoretical notion of projection. We return to these questions in the discussion of Experiment 3, which adds further perspective by employing an acceptability task rather than an inference task.

It is important to emphasize, however, that the confirmation of presuppositionspecific asymmetries through the statistical interaction above is independent of such

\footnotetext{
10 Another relevant comparison concerns fillers of the same form as the Conj-Ps-... items, but where the inference to be assessed corresponded to $p^{+}$, which should be endorsed on a parenthetical reading. These seem to exhibit an intermediate order effect, suggesting that to some extent, interpreting a presupposition in the first conjunct as projecting may further enhance the availability of a parenthetical reading.
} 
potential other effects. The results of Experiment 1 and 2 show that projection across conjunction exhibits at least a gradient asymmetry: we have clear evidence for left-toright filtering, and no evidence for right-to-left filtering.

Again, however, this leaves open the question of whether this asymmetry is merely gradient or categorical. In particular, Schlenker (2008a) suggests that left-to-right filtering is the default filtering mechanism, but that right-to-left filtering can be called upon as a kind of rescue strategy. A proponent of a view like that could point out that there were no contextual pressures in Experiments 1 and 2 that would promote right-to-left filtering, and thus that these experiments are consistent with a hypothesis on which right-to-left filtering is in principle available, but is only called upon when it is forced or facilitated by contextual pressures.

To test this hypothesis, we conducted a third experiment, which uses similar stimuli to those of Experiment 1 and 2, but uses an acceptability task rather than an inference task to explore whether $p$ projects even when there is contextual pressure against projection. In particular, we present the critical sentences in different contexts, which either establish that $p$ is true, or establish explicit ignorance on the part of the speaker, i.e., that the speaker does not know whether $p$ is true. An interpretation on which $p$ projects should be fully acceptable in the former context, whereas it should lead to unacceptability in the latter context, since it would be incoherent for the speaker to simultaneously declare her ignorance about $p$ and communicate that $p$ is taken for granted. Moreover, a context like the latter is precisely the kind of context where speakers would presumably resort to any rescue mechanisms which are available to them to interpret the speaker as rational and cooperative. Thus, if right-to-left filtering were available as a rescue mechanism, we would expect to find it when subjects assess a conditional of the form $\left\ulcorner\right.$ If $S_{p}$ and $p^{+}$, then $\left.q\right\urcorner$ in contexts in which the speaker has made it explicit that she is ignorant about whether $p$ is true; and thus we would expect to find higher acceptability ratings in this case than in the corresponding control of the form $\left\ulcorner\right.$ If $S_{p}$, then $\left.q\right\urcorner$ in the same context (once again, it is important to control acceptability ratings to this baseline in order to distinguish right-to-left filtering from local accommodation). If by contrast we find no such effect, this would suggest that filtering across conjunction is categorically asymmetric, such that right-to-left filtering is not available even as a rescue mechanism. ${ }^{11}$

\section{Experiment 3}

\subsection{Design}

The third experiment adapted the stimuli from the previous studies but utilized an acceptability task: before the critical conditional sentences, participants saw a brief context sentence, and then assessed the sentence's naturalness. The critical stimuli were as in Experiments 1 and 2: conditional sentences with a conjunction in their antecedent, of the form $\left\ulcorner\right.$ If $p^{+}$and $S_{p}$, then $\left.q\right\urcorner$ and $\left\ulcorner\right.$ If $S_{p}$ and $p^{+}$, then $\left.q\right\urcorner$. Control conditions used non-presuppositional variants, as in Experiment 2, which only differed from the

11 Thanks to Philippe Schlenker for providing the impetus for the general direction of this follow-up. 
presuppositional critical items in having non-presuppositional sentence-embedding verbs broadly similar in meaning to those employed in the presuppositional variants (i.e., sentences of the form $\left\ulcorner\right.$ If $p^{+}$and $S_{(p)}$, then $\left.q\right\urcorner$ and $\left\ulcorner\right.$ If $S_{(p)}$ and $p^{+}$, then $\left.q\right\urcorner$ ); a second control consisted of conditionals with non-conjunctive antecedents, containing either a presuppositional or a non-presuppositional embedding predicate. The second crucial manipulation varied the context, in that we manipulated whether the provided contexts supported the critical content $p$ or explicitly made clear that the speaker was ignorant about whether $p$. (17) provides an illustration of how these elements were phrased and displayed. Participants had to indicate how natural the sentence was in the given context on a 7-point scale ranging from 'completely unnatural' to 'completely natural'.

(17) Mary always was involved in a lot of sports, but I don't know whether she ever did any yoga. If Mary used to do Jivamukti yoga and she stopped doing yoga, then Matthew will interview her for his story.

Completely unnatural $\bigcirc \bigcirc \bigcirc \bigcirc \bigcirc \bigcirc \bigcirc$ Completely natural

Thus this design has three critical factors: Order (-First vs. -Second, as in Experiments 1 and 2), Embedding Type ( $P s$ vs. No-Ps, as in Experiment 2), and Context (Explicit Ignorance vs. Support). The addition of the final factor aims to create sufficient contextual pressure to allow any potential evidence for right-to-left filtering to emerge, even if right-to-left filtering may in general be dispreferred. In particular, the Explicit Ignorance contexts should lead to infelicity in the Conj-Ps-First condition if the presupposition projects, but this infelicity can be avoided via right-to-left filtering if it exists (it can also be avoided by way of local accommodation, which we control for separately as before).

\subsection{Materials and participants}

We adapted the materials from Experiments 1 and 2, consisting of conditionals embedding in their antecedents conjunctions containing presuppositional and nonpresuppositional expressions, in either conjunct order. The resulting 4 target sentence variations, schematically represented in (18), now appear preceded by a linguistic context which either supports the potentially projecting content $p$ or expresses explicit ignorance of it, by either conveying $p$ or explicitly stating I don't know whether $p$.
a. If $S_{p}$ and $p^{+}$, then $q$.
b. If $p^{+}$and $S_{p}$, then $q$.
c. If $S_{(p)}$ and $p^{+}$, then $q$.
d. If $p^{+}$and $S_{(p)}$, then $q$.

Conj-Ps-First

(19) and (20) illustrate the Conj-(No-)Ps-Second version of our running example in a SUPPORT versus EXPLICIT IGNORANCE contexts, respectively.

(19) Mary always was involved in a lot of sports, and she used to do yoga, too. If Mary used to do Jivamukti yoga and she \{stopped / now frowns on\} doing yoga, then Matthew will interview her for his story. 
(20) Mary always was involved in a lot of sports, but I don't know whether she ever did any yoga.

If Mary used to do Jivamukti yoga and she \{stopped / now frowns on\} doing yoga, then Matthew will interview her for his story.

In addition, within-item variants of the Simple-Ps and Simple-No-Ps conditions (with a non-presuppositional predicate in place of the presuppositional one) again provided a baseline comparison taking into account the possibility of local accommodation. (21) illustrates the two versions for the running example, which were paired with the same SUPPORT and EXPLICIT IGNORANCE contexts as above.

(21) If Mary \{has stopped / now frowns on\} doing yoga, then Matthew will interview her for his story.

24 critical items in a total of 12 versions were created (see Appendix for more detailed information on the stimuli), crossing Antecedent Type (First vs. Second vs. Simple), Embedding Verb (Ps vs. No-Ps), and Context (Support vs. Expl-Ign). The latter two factors were implemented as between-subject variations, i.e., the stimulusvariants were divided into 4 subsets to be assigned to different groups of participants; for each subset, three counter-balanced lists were created, so that each participant would see each item in one version, and overall see 8 items in each of the three Antecedent Type versions within the relevant subset across items. Making two of these factors between-subject served a number of purposes. First, it allowed us to keep the total number of critical items seen reasonable, despite the many variations per item. Second, precluding participants from seeing both presuppositional and nonpresuppositional variants aimed to avoid any potential confusion or noise due to lack of attention to the particular verb seen in a given trial; it also aimed to prevent strategic effects and insights into the manipulation from arising. Similar concerns arose for the context manipulation, though note that through the fillers, detailed below, each participant did see some variety of contexts throughout the entire experiment. This was not fully balanced, as we preferred to keep the filler variations identical across all groups, for the sake of comparability and uniformity.

Two types of filler items were added to get additional baselines for (un-)acceptability. The first consisted of variants of the conjunctive fillers we used before, which now contained a presupposition trigger that would also interact with the context manipulation. (22) provides an illustration. Crucially, the lack of any further embedding takes projection out of the equation, and thus most importantly provides a baseline for how unacceptable the presuppositional items are in Explicit Ignorance contexts. 16 such items were included, with contexts varied evenly within items across participants.

(22) Anna recently got married,...

i. .... and is expecting a baby.

(Acceptable Context)

ii....but I don't know whether she's going to have kids.

(Unacceptable Context)

Gerald is happy that Anna is pregnant and he will buy her a present. 
The second type of filler consisted of non-presuppositional conditional sentences with a simple, non-conjunctive, antecedent. For these, the context manipulation plays on the standard assumption that if-clauses must express information that is not at the time commonly believed to be false, i.e., they have to introduce open possibilities. The variants of the supportive contexts here violated this condition, in that they established some proposition $p$, while the if-clause contained the negation of $p$ (putting the negation in the antecedent of the conditional allowed us to make the contexts fully parallel to those for the critical items); in contrast, the Explicit Ignorance contexts were fully in line with this requirement. (23) provides an illustration.

(23) Ethan is planning a trip,...

i. .... and he'll go to England first.

(Unacceptable Context)

ii. ...but I don't know whether he's coming to England.

(Acceptable Context)

If Ethan isn't coming to England, then Olivia will invite somebody else for dinner.

16 such fillers were included, again with contexts evenly varied within items across participants, such that all participants saw at least 16 equivalents of Support contexts, and 16 equivalents of Expl-Ign contexts, regardless off which type of context their group was assigned to for the critical items.

We recruited 126 students (all self-reported native speakers of English) through the Psychology Subject Pool at the University of Pennsylvania, who took the experiment on a lab computer and received course credit for their participation. An archived version of the experiment can be accessed online at http://spellout.net/ibexexps/ SchwarzLabArchive/IncrSymExp3/experiment.html?Home=T.

\subsection{Results}

The mean acceptability ratings for critical conditions are illustrated in Fig. 3, separately for Expl-Ign and Support contexts. The outermost gray bars within each subplot show the effect of context on the simple, non-conjunctive control conditions. As expected, the non-presuppositional variants on the right are not affected by the context manipulation. By contrast, the Simple-Ps condition exhibits low ratings for the Expl-Ign context, but high ratings for the Support context, establishing the effectiveness of the methodology. Next, the non-presuppositional conjunctive conditions, just right of the middle in the respective panels, also do not seem to exhibit any variation by context or, for that matter, conjunct order. Turning to the critical conditions, the conditions with the trigger in the second conjunct also seem comparably acceptable across contexts. Only when the trigger is introduced in the first conjunct does context seem to matter, with lower ratings in the Expl-Ign context. Indeed, the ratings here appear very close to those of the Simple-Ps condition. Results for the filler conditions further confirm the effectiveness of the overall approach of manipulating acceptability by varying contexts, with generally even results across the various groups assigned to the 

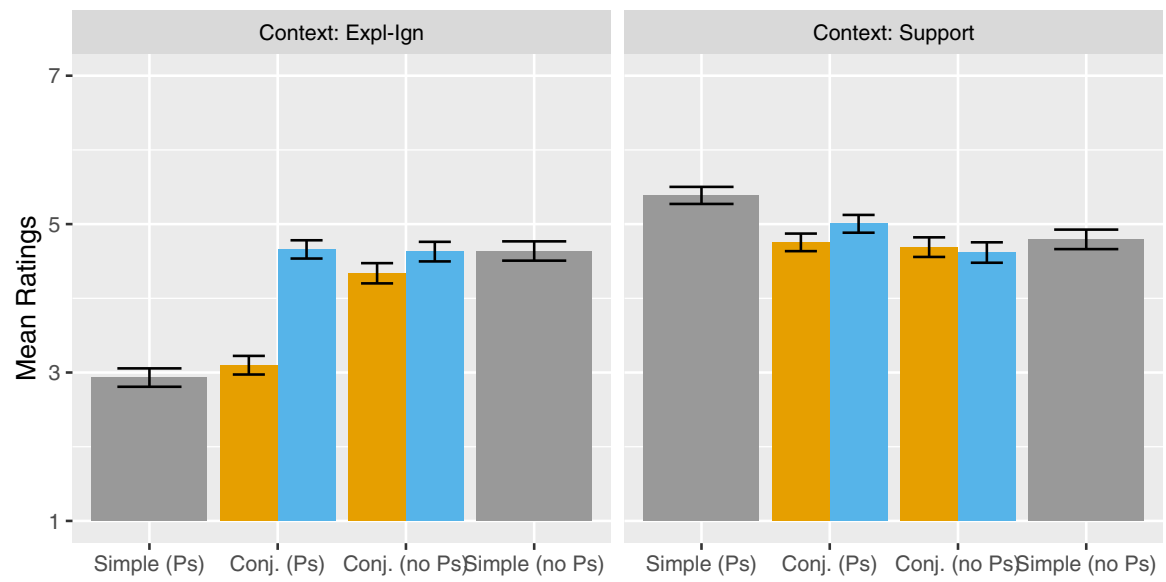

Fig. 3 Mean acceptability ratings by context and condition in Experiment 3

different levels of the two between subject-variables; see Appendix for more detailed illustration.

In order to assess the crucial comparisons statistically, we conducted linear mixed effect model analyses using the lme 4 package for $\mathrm{R}$, with an overall parallel approach to the logistic regression models for the previous experiments (specifically with regards to choosing maximal random effect structures that would converge while avoiding random effect correlations approaching 1). To assess all the factors together, we first conducted a 3-way interaction analysis using treatment coding, with Conj-Ps-FirstExpl-Ign as the baseline. (See Appendix for full details on the model.) Focusing on the conjunction comparisons, there is a significant 3-way interaction $(t=3.09)$, showing that Order and Context interact differently for the Ps and No-Ps conditions. In addition, there were corresponding significant 2-way interactions at the relevant baseline levels: for the Expl-Ign conditions, there was a significant interaction between Order and Embedding Type $(t=5.80)$; for the presuppositional conditions, a significant interaction between Order and Context $(t=6.56)$; and for the First conditions, with the embedding predicate in the initial conjunct, a significant interaction between Embedding Type and Context $(t=3.39)$. While $t$-values greater than 2 can already be seen as indicators of statistical significance, we also ran three $2 \times 2$ interaction analyses with centered predictors on the relevant subsets of the data (i.e., successively selecting data corresponding to the baseline level of each predictor), using model comparisons to obtain $p$-values as indicators of significance; all three 2-way interactions were significant here as well ( $p$ 's $<.01)$; see Appendix for details. Turning to the more detailed nature of these 2-way interactions, they are all driven by the ConjPs-First-Expl-Ign condition yielding lower acceptability than the other conjunction conditions; this is confirmed in the 3-way interaction analysis by significant simple effects relative to Conj-Ps-Second-Expl-Ign $(t=10.31)$, reflecting asymmetry; relative to Conj-No-Ps-First-Expl-Ign $(t=4.33)$, showing that the effect is specific to $P s$; 
and relative to Conj-Ps-First-Support $(t=5.86)$, confirming the effect of Context. Finally, and importantly, there was no significant difference relative to the Simple-PsExpl-Ign condition $(\beta=-0.14, S E=0.15, t=-0.94)$, i.e., having a later conjunct support a presupposition has no effect on acceptability, as the result is indistinguishable from that for sentences that merely contain the presuppositional conjunct.

As a further point, it's worth highlighting that the overall pattern is remarkably uniform across triggers (see graph showing results by trigger in Appendix for details). While the acceptability of both Simple-Ps and Ps-First varies across triggers (with particularly high acceptability for aware, perhaps due to relative ease of local accommodation for this trigger), the two conditions show comparable acceptability levels in Expl-Ign for each of the triggers.

\subsection{Discussion}

This experiment provided further clear evidence for the existence of an order asymmetry in presupposition projection from conjunction. Moreover, we found no evidence in this experiment for the existence of a right-to-left filtering option that becomes available when there is contextual pressure to utilize it, namely to avoid infelicity. If such an option existed, we would expect to find direct evidence for right-to-left filtering in cases where the projecting content conflicts with explicit statements of ignorance provided in the preceding context. In such cases, right-to-left filtering would provide a way to interpret the speaker as being coherent and their utterance felicitous; without this option, the speaker will be interpreted as incoherent and the utterance infelicitous. A set-up like this seems ideally suited for invoking a pragmatic rescue mechanism of this sort. Yet, in the present acceptability task, subjects' acceptability judgments did not distinguish between the trigger-first condition (sentences of the form $\left\ulcorner\right.$ If $S_{p}$ and $p^{+}$, then $\left.q\right\urcorner$ ) and the control presupposition condition (sentences of the form $\left\ulcorner\right.$ If $S_{p}$, then $q\urcorner$ ): both were found to be equally unacceptable in Explicit Ignorance contexts. That suggests that the only rescue mechanism available here is local accommodation, not right-to-left filtering. ${ }^{12}$

Of course, non-existence arguments pose a tall order, and we still cannot rule out with certainty that right-to-left filtering does exist and can be invoked in some circumstances other than those we tested. In particular, one could imagine that rightto-left filtering exists but requires even more stringent conditions for it to become available. For instance, one could imagine that right-to-left filtering is recruited only when both (i) it would rescue a sentence and (ii) there is a salient reason why the speaker didn't use the default left-to-right order. ${ }^{13}$ If this were so, then right-to-left filtering would not necessarily be recruited in the kinds of cases we tested (and may be very hard to detect in general). So we cannot rule out this possibility. However, the absence of evidence for right-to-left filtering even in the set-up given in Experiment 3, which was designed to introduce maximal contextual pressure to call on right-to-left filtering, is at least strongly suggestive that right-to-left filtering is not possible at all

\footnotetext{
12 As noted above, the availability of local accommodation seems to vary somewhat between triggers, but importantly, the two mentioned conditions pattern together uniformly for all triggers.

13 Thanks to an anonymous reviewer for discussion on this point.
} 
for conjunction. In other words, this final experiment provides pro tanto support for categorical asymmetry in filtering across conjunction, and shifts the dialectical burden onto those who wish to argue that there is right-to-left filtering.

Our results here also help answer two questions raised by the previous two experiments. First, we find no evidence of projection of any kind in the non-presuppositional controls in the acceptability task: there were no significant differences between acceptability judgments in the support vs. ignorance contexts for these stimuli. This is exactly in line with expectations from the point of view of a traditional distinction between triggers and non-triggers. Likewise, we saw no evidence in this case for projection from trigger-second presuppositional conditions, again, exactly in line with traditional theories on which we would expect the presupposition to be completely filtered in those cases. For reasons we discuss further below, we take this to provide evidence that the surprisingly high inferences observed above, both in the non-presuppositional controls and in the trigger-second condition, are evidence of some kind of defeasible pragmatic inference or defeasible failure to draw the relevant inferences, possibly encouraged by the nature of the inferential task, that can —and should—be distinguished from presupposition projection.

Second, above we raised the possibility that our lack of evidence for right-to-left filtering came from the interaction of (i) real right-to-left filtering for some trials together with (ii) projective parenthetical readings, having nothing to do with presupposition projection, for other trials, which together evened out to match projection rates in the presuppositional control. Since in the present experiment we found no evidence of projective parenthetical readings in the non-presuppositional conditions (which would have led to a clash with the ignorance context but not with the supporting context), we cannot explain away the lack of evidence for right-to-left filtering here in the same way; and presumably this also counts as evidence against that explanation in the first two experiments. ${ }^{14}$

\section{General discussion}

\subsection{The verdict on right-to-left filtering}

The central question our experiments aimed to address was whether we find asymmetry in presupposition projection from conjunction, i.e., whether the linear order of

\footnotetext{
14 An anonymous referee raises an interesting alternative explanation of the results in this experiment: namely, that (i) projection is always cumulative (there is no filtering); and (ii) what explains the observed difference in acceptability by order is simply linear distance from the avowal of ignorance. But (i) does not fit well with our first two experiments, where we found apparent evidence for left-to-right filtering. And it looks like (ii) predicts that adding any suitably long intervening material should be enough to rescue a presuppositional sentence in ignorance contexts, whereas in fact presuppositional sentences only seem to be rescued if the intervening material entails the presupposition, as illustrated by the contrast between (i) and (ii):

(i) \# Jacob has been traveling a lot, but I'm not sure where he is this week. If Jacob is friends with Emily and Emily is happy that he is in France, then she will call him soon.

(ii) Jacob has been traveling a lot, but I'm not sure where he is this week. If Jacob is in France and Emily is happy that he is in France, then she will call him soon.
} 
a conjunct containing a presupposition trigger and another conjunct that entails the relevant presupposition affects whether the presupposition projects.

We assessed this by embedding conjunctions of the form $\left\ulcorner S_{p}\right.$ and $\left.p^{+}\right\urcorner$and $\left\ulcorner p^{+}\right.$and $\left.S_{p}\right\urcorner$ in the antecedents of conditionals, using both an inference task (Experiments 1 and 2 ) and acceptability judgments (Experiment 3 ) to ascertain whether subjects took $p$ to project out of such conditionals. Using $p^{+}$as the non-presuppositional conjunct, rather than $p$, allowed us to control for issues of redundancy which Rothschild and others have pointed out confound some previous claims on this matter. Comparing projection to both simple (non-conjunctive) presuppositional and non-presuppositional baselines allowed us to control for local accommodation.

Taken together, our experiments show evidence for asymmetry in projection across conjunction. In all three experiments, we found evidence for lower rates of projection from sentences of the form $\left\ulcorner p^{+}\right.$and $\left.S_{p}\right\urcorner$ than for sentences of the form $\left\ulcorner S_{p}\right.$ and $\left.p^{+}\right\urcorner$. The second experiment, moreover, showed that this is not just due to general order effects independent of presuppositionality: while we did, intriguingly, find evidence for such general order effects for both presuppositional and non-presuppositional predicates, they do not suffice to account for the presupposition-specific order effect in the first two experiments. At least in this paradigm, then, this provides evidence that leftto-right filtering is much easier to access than right-to-left filtering, i.e., that there is at least a gradient asymmetry in presupposition projection from conjunction. Moreover, we were unable to find any evidence for right-to-left filtering at all, even when we set up the context to promote use of right-to-left filtering as much as possible in Experiment 3: in no case did projection from sentences of the form $\left\ulcorner S_{p}\right.$ and $\left.p+\right\urcorner$ turn out lower than projection from simple presuppositional sentences of the form $\left\ulcorner S_{p}\right\urcorner$. In other words, the existence of a later conjunct that could in principle filter the presupposition made no difference at all in our results. While we of course cannot rule out with absolute certainty the possibility that some evidence for right-to-left filtering across conjunction could still turn up in other experimental paradigms, this provides pro tanto evidence that, when it comes to conjunction, only left-to-right filtering is available: in other words, that projection from conjunction is categorically asymmetric.

\subsection{Methodological implications for investigating presupposition projection}

There were two surprising aspects in the results of our first two experiments: first, even in variants where the presupposition was introduced in the second conjunct, inference rates were higher than in simple baseline conditions, suggesting, in descriptive terms, that left-to-right filtering was not operative as consistently as expected based on standard theoretical accounts. This could be due to various task-specific effects, which could be followed up on in various ways, though it's not clear that any theoretically important issues are at stake (recall that one simple explanation would be that the entailment relation between conjuncts was not always sufficiently transparent). The second surprising finding, which at first sight may seem to be of more immediate theoretical relevance, was that we also find increased inference endorsement rates for controls with non-presuppositional embedding predicates (such as be sure, enjoy, etc.) in Experiment 2. This finding is reminscent of recent experimental reports of 
a gradient spectrum of projection effects across various expressions, including both predicates that are traditionally considered presupposition triggers, and others that are not (Tonhauser 2016; Tonhauser et al. 2018). And at first sight, this aspect of our results could be taken to support the hypothesis that the distinction between projective and non-projective content is much less clear-cut than traditional work has assumed, with important implications for the nature and source of presuppositional content and its projective properties. ${ }^{15}$

The change-up in the task utilized in the third experiment, however, sheds interesting further light on these two effects, as they were not replicated. There, the critical condition in which the presuppositional or non-presuppositional sentence-embedding conjunct came second yielded no difference between judgments of acceptability based on context (Support vs. Expl-Ign). In other words, once we looked at acceptability judgments rather than inference tasks, there no longer is any indication of lack of left-to-right filtering or gradient projection from non-presuppositional embedding predicates. In other words, everything behaved just as we would expect it to from the point of view of traditional theories: sentences of the form $\left\ulcorner\right.$ If $p^{+}$and $S_{p}$, then $\left.q\right\urcorner$ or of the form $\left\ulcorner\right.$ If $p^{+}$and $S_{(p)}$, then $\left.q\right\urcorner$ do not project $p$.

Descriptively speaking, we thus have a split verdict between the inference tasks and the acceptability task, and in a sense, this is not surprising. It has been known since Grice (1989)'s seminal work that inference is a multifarious thing, and can go well beyond the truth-conditional or presuppositional content of a sentence. Thus the fact that subjects tend to draw certain inferences from clauses appearing in embedded, entailment-canceling environments, does not necessarily mean that the relevant content has projected in the sense that theorists of presupposition should care about. Crucially, we need a way to operationalize the notion of presupposition projection. Arguably, acceptability tasks give us just that. If subjects draw an inference just because it is a natural conclusion to draw for any of a variety of pragmatic reasons short of entailment or presupposition, then they will tend to relinquish that inclination when there is pragmatic pressure to do so, as in the Explicit Ignorance contexts of Experiment 3. By contrast, if the inference in question is a semantic presupposition, this will not be a possibility: beyond the (marked) rescue mechanism of local accommodation, subjects will not have an alternative to interpreting the presupposition at the utterance level, and in turn seeing the utterance as infelicitous and the speaker as incoherent. Thus comparing contexts which support the inference to contexts in which it has been made clear that the speaker is ignorant about the inference provides a way to distinguish a broad class of natural and invited pragmatic inferences from those that are really encoded as presuppositions, and thus have no choice but to project. ${ }^{16}$ The theoretical upshot is that we should think twice before embracing a notion of presupposition projection that is gradient based on results from inference tasks alone. In methodological terms, we strongly recommend at least a two-pronged approach, with careful attention paid to results stemming from the evaluation of acceptabilty in different contexts.

\footnotetext{
15 Note, however, that other work with parallel tasks is more consistent with a traditional categorical distinction between triggers and non-triggers, while allowing for some pragmatic variation in projection strength; see in particular Djärv and Bacovcin (2017).

16 Cf. a similar move made in Mandelkern (2016) in arguing against approaches to the Proviso Problem on which non-conditional inferences are just pragmatic inferences, not semantic presuppositions.
} 
Of course, all this still leaves open questions about how to explain the other pragmatic inferences. We will not try to account for these, but will make one suggestion here, following Geurts and Pouscoulous (2009, sec. 2). It may well be that inference tasks to some degree invite subjects to make the inference in question if it is compatible with the assertion, since the content in question is right there before the subjects' eyes. This, for instance, might account for the projection observed in inference tasks for sentences of the form $\left\ulcorner\right.$ If $p^{+}$and $S_{p}$, then $\left.q\right\urcorner$, possibly in combination with the suggestion above that subjects may fail to notice the relevant entailment relation. That is, subjects may fail to observe the entailment between $p^{+}$and $p$, and thus the fact that the presupposition fails to project, when they are "invited" to infer that $p$ is true by the stimulus. By contrast, in a context where the inference to $p$ will lead to unacceptability, subjects will be prompted to think more carefully and will notice that $p^{+}$ entails $p$ and thus that the left conjunct filters the presupposition of the right conjunct.

This idea is obviously tentative and requires further exploration. Let us emphasize, however, that whatever we ultimately make of the surprising apparent 'projection' effects observed in the inference tasks we believe that the fact that the acceptability judgments in Experiment 3 are exactly in line with what traditional accounts predictwith no projection from sentences of the form $\left\ulcorner\right.$ If $p^{+}$and $S_{p}$, then $\left.q\right\urcorner$ or of the form $\left\ulcorner\right.$ If $p^{+}$and $S_{(p)}$, then $\left.q\right\urcorner$ - provides substantial support for distinguishing real presupposition projection from a variety of other pragmatic inference patterns.

\subsection{Comparisons to previous work}

Ours is not the first attempt to explore the (a-)symmetry of projection behaviour. In this section we will briefly discuss how our results relate to those of a previous study in Chemla and Schlenker (2012) — a study whose conclusions pointed in different directions from ours. Chemla and Schlenker's study is the first experimental approach we know of to questions of (a-)symmetry in presupposition projection. They employ both inferential and acceptability experiments to investigate the projection of sentences in which a presupposition trigger appears either sentence-initially or sentence-finally, with its presupposition being satisfied by material that preceded or followed it, respectively. In particular, their inferential experiments looked at (the corresponding French versions of) sentences like (24) versus (25), containing a presupposition trigger (French aussi, 'too') and material that could plausibly be taken to satisfy its presupposition, either preceding or following it. (In addition to disjunctions like (24) and (25), they investigated corresponding conditionals and unless-sentences.)

(24) Ann will not decide to study abroad, or her brother too will make a reasonable decision.

(25) Ann's brother too will make a reasonable decision, or Ann will not decide to study abroad.

If the non-presuppositional disjunct is interpreted as relating to the presupposition of too- which requires a small bit of fairly natural accommodation — then these sentences can be taken to suggest that studying abroad would be a reasonable decision for Ann. Chemla and Schlenker (2012) then measured to what extent participants concluded the inferences in (26) and (27), the rationale being that if the material from the nonpresuppositional disjunct was considered, participants would only conclude the weak 
inference in (26) (which contextually corresponds to a conditional presupposition that is relativized to the other disjunct); conversely, if the presupposition of the trigger were simply to project globally (with too being related to Ann), they would conclude the strong inference in (27).

(26) Studying abroad would be reasonable for Ann.

(27) Ann will make a reasonable decision.

In their results, they found that the 'conditional' inference in (26) was preferred in the canonical order, providing evidence that material that precedes the trigger is indeed taken into account, as expected by any theory incorporating a form of left-to-right filtering. More surprisingly, they also found that the conditional inference was also endorsed more than the unconditional one in the inverse order, suggesting that material that follows the trigger is also taken into account, thus supporting a theory that also incorporates some form of right-to-left filtering. ${ }^{17}$

The study by Chemla and Schlenker (2012) was an important first step towards addressing questions about (a-)symmetric effects in projection. There are two noteworthy ways in which our approach goes beyond that of Chemla and Schlenker (2012). First, Chemla and Schlenker did not look at conjunction, which, again, is taken as the paradigmatic case for asymmetry. At this stage of inquiry, as we discuss further in a moment, we must leave open the possibility that projection (a-)symmetries differ across connectives, and thus careful exploration of each connective is required. And indeed, if we take both our results and those of Chemla and Schlenker at face value, they point to a divergence of just this kind. Having said that, there is, second, some reason to hesitate about taking Chemla and Schlenker's results at face value, which is that their study focuses on additive particles. The motivation for this is to control for local accommodation, which is thought to be more difficult with additive particles. But as Chemla and Schlenker themselves discuss, additive particles differ in their properties from other presupposition triggers in important and relevant respects; in particular, these particles' presuppositions project in quite peculiar ways, as discussed in Soames (1979), Karttunen and Peters (1979), Chemla and Schlenker (2012), Romoli (2012) and Mandelkern and Romoli (2017) among others. Thus it is not clear how far we can generalize conclusions about presupposition projection in general from projection data concerning additive particles. Finally, note that the main results reported by Chemla and Schlenker come from an inference task, which comes with the complications discussed above. (They tried using an acceptability task as well, but did not get conclusive results for that.) 18

\footnotetext{
17 Chemla and Schlenker (2012) did not investigate the potential interaction between type of inference and order, which would be, in our mind, the most convincing measure of asymmetry.

18 Schwarz (2015) also investigates (a-)symmetry in projection by using 'again' in antecedent-initial vs. antecedent-final conditional sentences. His results are broadly comparable to those of Chemla and Schlenker (2012). However, he also doesn't look at conjunctions, and, again, there is a question as to whether 'again' brings in the same idiosyncratic issues brought in by 'too'.
} 


\section{Conclusion and further directions}

Projection across conjunction has traditionally been taken to provide central evidence that the mechanisms underlying presupposition projection in general are asymmetric. Once we control for independent issues about redundancy, however, intuitive judgments become much less clear, and the recent literature has been split on whether projection across conjunction is asymmetric after all. Through experiments which control for issues of redundancy and distinguish filtering from local accommodation, and using both inference and acceptability tasks, we have found evidence that projection across conjunction is indeed asymmetric. While this could be the case either gradiently or categorically, the acceptability task in the last experiment provides at least strongly suggestive evidence for the latter, stronger conclusion: that projection across conjunction is categorically asymmetric.

An important question which our results leave open concerns the (a-)symmetry of other connectives. We cannot assume ex ante that the (a-)symmetry properties of projection is unifrom across different connectives, and indeed disjunction in particular has frequently been claimed to exhibit right-to-left filtering, as exhibited by examples like (28) (following Karttunen 1973 a.o.):

(28) Either Mary stopped doing yoga, or she never did yoga.

It's clear that we do not infer from (28) that Mary used to do yoga, a fact which is naturally taken as evidence that there is right-to-left filtering across disjunctions. But, as for conjunction, care must be taken here to distinguish filtering from independent pragmatic issues. (28) has the form $\left\ulcorner S_{p}\right.$ or not $\left.p\right\urcorner$. If $p$ projected from a sentence of this form, we could then conclude $S_{p}$ is true, making the right disjunct redundant. So in cases like this, as has been observed since Gazdar (1979), there is independent pressure to locally accommodate the presupposition. ${ }^{19}$ This issue can be avoided, as for conjunctions, by looking instead at sentences of the form $\left\ulcorner S_{p}\right.$ or not $\left.p^{+}\right\urcorner$, like (29):

(29) Either Mary stopped doing yoga, or she never did Jivamukti yoga.

Here, as for conjunctions, judgments about projection become less clear, and experimental work is needed to assess to what degree subjects will infer that Mary used to do yoga from (29), and to what degree that differs from local accommodation. This will allow us to clarify symmetry properties across different connectives. Finding differences across connectives would pose a striking explanatory challenge, and might suggest that the projection properties of connectives are encoded as a matter of semantic convention (the line suggested by classic work in dynamic semantics like Heim 1983). A uniform picture, by contrast, would be at least prima facie more compatible with approaches which aim to explain projection properties in non-conventional terms, like Schlenker (2008a) and Rothschild (2011/2015).

\footnotetext{
19 See Hirsch and Hackl (2014) for a proposal along these lines, as well as experimental data consistent with the notion that with the trigger in the first disjunct, we are not dealing with right-to-left filtering but pragmatically forced local accommodation. Hirsch et al. (2018) provide further evidence for the viability of this account in terms of online processing time course based on visual world eye tracking data.
} 
Another important question which our discussion leaves open is the precise root of the asymmetry which we have found evidence for. Is the asymmetry a matter of linear order, as parsing-based approaches like Schlenker (2008a)'s would suggest, or is it a matter of structure, as classical dynamic approaches would suggest (Chierchia 2009)? This is an important question for understanding where in the linguistic system presuppositions are processed. Conjunctions, at least in languages like English, are unlikely to help us answer this question, as linear and structural asymmetries coincide here (on standard syntactic approaches); recent insight on this question has come from cross-linguistic data (Ingason 2016; Chung 2017), as well as constructions in English with flexible linear order, like conditionals (Mandelkern and Romoli 2017).

Investigating (a-)symmetry in presupposition projection promises insights into the architecture of one characteristic component of natural language. In addition, it may inform theories of redundancy (which include both symmetric and asymmetric versions), anaphora, and epistemic modals (which are argued in Mandelkern (2019) to be interpreted relative to an exclusively symmetric system of local contexts). The study of these latter phenomena, likewise, may indirectly help determine the best theory of presupposition projection. Many more new questions are raised here than answered, but we hope that our experimental results, as well as the paradigm we developed, advance our understanding of these subtle issues.

Open Access This article is distributed under the terms of the Creative Commons Attribution 4.0 International License (http://creativecommons.org/licenses/by/4.0/), which permits unrestricted use, distribution, and reproduction in any medium, provided you give appropriate credit to the original author(s) and the source, provide a link to the Creative Commons license, and indicate if changes were made.

\section{Appendix}

All the materials we used for running the experiments and analyzing the results can be found on the Open Science Framework platform at https://osf.io/2b9m7/.

\section{Experiment 1 details}

\subsection{Experimental stimuli}

\section{Cricital Items}

1. a. If Emily is happy that Jacob is in France and he is in Paris,...

(Conj-Ps-First)

b. If Jacob is in Paris and Emily is happy that he is in France, ...

(Conj-Ps-Second)

c. If Jacob is in France, ...

(Simple-No-Ps)

d. If Emily is happy that Jacob is in France, ...

(Simple-Ps)

...then $\{$ she/Emily $\}$ will call him soon

2. If $\{($ Emma is happy that Michael lives in Japan) [and] (he lives in Tokyo) $\}$, then she will go visit him

3. If Madison is happy that Joshua plays an instrument and he plays the piano, then she will invite him to the party 
4. If Abigail is happy that Matthew travelled to Germany and he travelled to Berlin, then she will ask him to write a post on her blog

5. If Olivia is happy that Ethan is coming to England and he is coming to London, then she will invite him for dinner

6. If Isabella is happy that Andrew plays a sport and he plays basketball, then she will ask him to train with her

7. If Hannah is happy that Daniel sells flowers and he sells roses, then she will go buy flowers from him

8. If Samantha is happy that Anthony designs clothes and he designs shirts, then she will ask him to work for her

9. If Ava is aware that Christopher smokes cigarettes and he smokes Marlboros, then she will tell him about the recent class action suit

10. If Ashley is aware that Joseph likes music and he likes classical music, then she will give him an anthology of Beethoven

11. If Sophia is aware that William likes musical instruments and he likes violins, then she will ask him to play in her orchestra

12. If Elizabeth is aware that Alexander drinks soda and he drinks coke, then she will buy some coke at the grocery store

13. If Alexis is aware that Ryan drives and he drives a Toyota, then she will get a ride from him

14. If Grace is aware that David likes to eat out and he likes to eat at Mexican restaurants, then she will not eat at home

15. If Sarah is aware that Nicholas eats meat and he eats pork, then she will bring her own lunch

16. If Alyssa is aware that Tyler likes animals and he likes dogs, then she will ask him to walk her dog

17. If Emily has stopped playing with toys and she used to have fun with toy cars, then Jacob will buy her racing video games for her birthday

18. If Emma has stopped reading novels and she used to enjoy sci-fi novels, then Michael will take her to the movies

19. If Madison has stopped drinking and she used to enjoy vodka, then Joshua will invite her to his group

20. If Abigail has stopped doing yoga and she used to practice Jivamukti yoga, then Matthew will interview her for his story

21. If Olivia has stopped going to the gym and she used to frequent the gym on campus, then Ethan will ask her to train with him

22. If Isabella has stopped drinking coffee and she used to drink espresso, then Andrew will suggest that she order tea

23. If Hannah has stopped skipping classes and she used to skip Physical Education, then Daniel will not report her to the principal

24. If Samantha has stopped travelling to Italy and she used to go to Rome, then Anthony will offer to take her on his next trip to Spain

25. If Ava continues visiting museums and she has been frequenting science museums, then Christopher will have a lot to talk to her about

26. If Ashley continues watching sports and she has been watching baseball matches, then Joseph will talk to her about the World Series

27. If Sophia continues going out to eat and she has been eating at expensive restaurants, then William will get her a Wine and Dine magazine subscription

28. If Elizabeth continues eating meat and she has been eating red meat, then Alexander will not want to go out to eat with her

29. If Alexis continues failing exams and she has been flunking end-of-the-year exams, then Ryan will not let her study abroad 
30. If Grace continues hosting parties and she has been throwing massive parties, then David will go live somewhere else

31. If Sarah continues adopting pets and she has been adopting cats, then Nicholas will suggest she get a hamster

32. If Alyssa continues working in academia and she has been working for Harvard, then Tyler will nominate her for the research committee

\section{Fillers}

a. Presuppositional fillers with complex antecedent (4 for each trigger; conjunct order varied within item across participant groups):

If Shirley has stopped playing basketball and she used to be a WNBA player, then Juan will ask her to teach basketball to disadvantaged kids in the summer

Inferences (varied within item across participant groups):

(c) Juan will ask Shirley to teach basketball to disadvantaged kids in the summer

$(\mathrm{p}+)$ Shirley used to be a WNBA player

b. Non-presuppositional fillers with complex antecedent (4 with 'hope', 'doubt', 'try' and 'plan' in complex conjunct; conjunct order varied within item across participant groups):

If Hannah is trying to go study abroad and she is looking at universities in Canada, then John will tell her about his experience

Inferences (varied within item across participant groups):

(c) John will tell Hannah about his experience

(p) Hannah is looking at universities in Canada

$(\mathrm{p}+)$ Hannah will go study abroad ${ }^{20}$

c. Presuppositional fillers with simple antecedent (2 for each trigger):

If Ralph has stopped working at night, then Pamela will invite him out for dinner

Inference:

(c) Pamela will invite Ralph out for dinner

d. Conjunctive fillers with presupposition (1 for each trigger except 'continue' (due to a clerical error): Kevin is happy that Nora is a musician - she's a pianist - but he doesn't like the music she plays.

Inferences (varied within item across participant groups):

(c) Kevin doesn't like the music Nora plays

(p) Nora is a musician

$(\mathrm{p}+)$ Nora is a pianist ${ }^{21}$

e. Conjunctive fillers with no presupposition (5 total):

Bill likes races, in particular horse races, but Scarlett doesn't like sports involving animals

Inferences (varied within item across participant groups):

(conjunct 1) $(\mathrm{p}+)$ Bill likes horse races

(conjunct $1(\mathrm{p}))$ Bill likes races

(conjunct 2) (c) Scarlett doesn't like sports involving animals

\subsection{Details of results and statistical analysis}

See Table 1 and Figs. 4 and 5.

\footnotetext{
20 Note that the simple conjunct did not entail $\mathrm{p}$ for all items due to challenges in making the sentences plausible.

21 Note that the parenthetical did not entail $\mathrm{p}$ for all items due to challenges in making the sentences plausible.
} 
Table 1 Estimated coeffecients, standard errors, Wald's $\mathrm{z}$, and $p$ values from logistic mixed effect model of the form (Answer $==$ "Yes") $\sim$ condition + (1। subject $)+(1+$ condition I item $)$ for Experiment 1

\begin{tabular}{lllll}
\hline Planned comparisons ... & $\beta$ & $S E$ & $z$ & $p$ \\
\hline Conj-Ps-Second as baseline, vs. & & & \\
Conj-Ps-First & 1.68 & 0.21 & 8.01 & $<. \mathbf{0 0 1}$ \\
Simple-Ps & 1.47 & 0.21 & 7.15 & $<.001$ \\
Simple-No-Ps & -2.28 & 0.22 & -10.13 & $<.001$ \\
Conj-Ps-First as baseline vs. & & & \\
Simple-Ps & -0.21 & 0.21 & -1.00 & $=.315$ \\
Simple-No-Ps & -3.96 & 0.25 & -15.77 & $<.001$ \\
\hline
\end{tabular}

Significant $\mathrm{p}$-values $(\mathrm{p}<0.05)$ are reported in bold

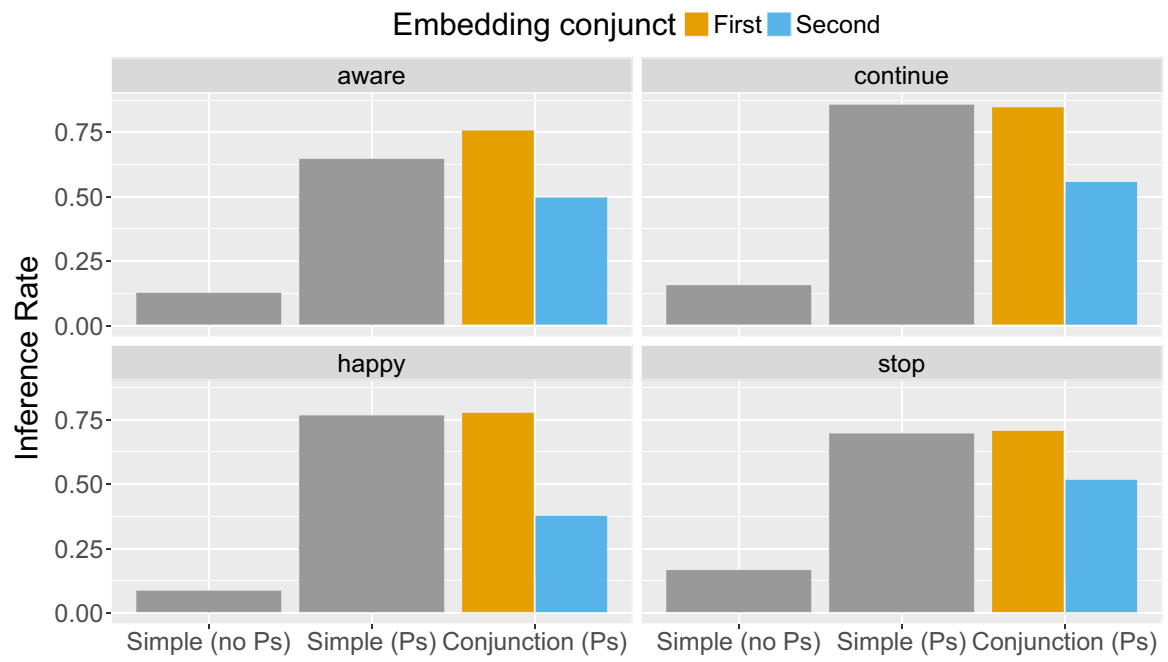

Fig. 4 Mean inference rates of $p$ per condition by trigger in Experiment 1

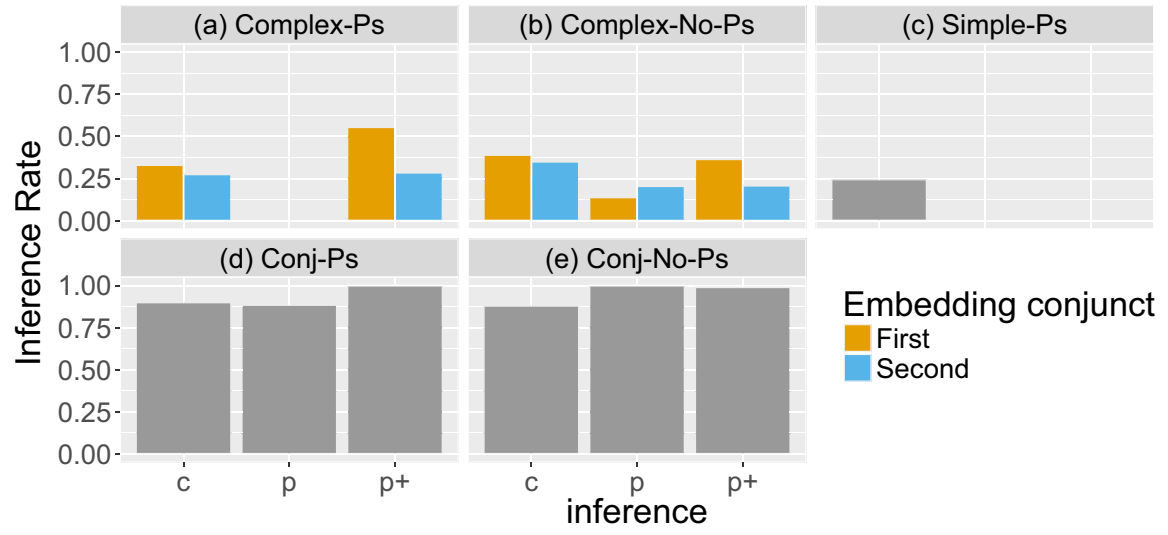

Fig. 5 Mean inference rates for fillers by inference type and conjunct order (where applicable) in Experiment 1 


\section{Experiment 2 details}

\subsection{Experimental stimuli}

\section{Cricital Items}

1. a. If Emily is happy that Jacob is in France and he is in Paris, then she will call him soon

b. If Jacob is in Paris and Emily is happy that he is in France, then she will call him soon

c. If Emily was hoping that Jacob is in France and he is in Paris, then she will call him soon ${ }^{22}$

d. If Jacob is in Paris and Emily was hoping that he is in France, then she will call him soon

2. If Emma \{is happy / was hoping\} that Michael lives in Japan and he lives in Tokyo, then she will go visit him

3. If Madison \{is happy / was hoping \} that Joshua plays an instrument and he plays the piano, then she will invite him to the party

4. If Abigail \{is happy / was hoping\} that Matthew travelled to Germany and he travelled to Berlin, then she will ask him to write a post on her blog

5. If Olivia \{is happy / was hoping that $\}$ that Ethan is coming to England and he is coming to London, then she will invite him for dinner

6. If Isabella \{is happy / was hoping that $\}$ that Andrew plays a sport and he plays basketball, then she will ask him to train with her

7. If Hannah \{is happy / was hoping that $\}$ that Daniel sells flowers and he sells roses, then she will go buy flowers from him

8. If Samantha \{is happy / was hoping that $\}$ that Anthony designs clothes and he designs shirts, then she will ask him to work for her

9. If Ava is \{aware / sure\} that Christopher smokes cigarettes and he smokes Marlboros, then she will tell him about the recent class action suit

10. If Ashley is \{aware / sure \} that Joseph likes music and he likes classical music, then she will give him an anthology of Beethoven

11. If Sophia is \{aware / sure\} that William likes musical instruments and he likes violins, then she will ask him to play in her orchestra

12. If Elizabeth is \{aware / sure\} that Alexander drinks soda and he drinks coke, then she will buy some coke at the grocery store

13. If Alexis is \{aware / sure \} that Ryan drives and he drives a Toyota, then she will get a ride from him

14. If Grace is \{aware / sure\} that David likes to eat out and he likes to eat at Mexican restaurants, then she will not eat at home

15. If Sarah is \{aware / sure\} that Nicholas eats meat and he eats pork, then she will bring her own lunch

16. If Alyssa is \{aware / sure\} that Tyler likes animals and he likes dogs, then she will ask him to walk her $\operatorname{dog}$

17. If Emily \{has stopped / frowns on\} playing with toys and she used to have fun with toy cars, then Jacob will buy her racing video games for her birthday

18. If Emma \{has stopped / frowns on\} reading novels and she used to enjoy sci-fi novels, then Michael will take her to the movies

19. If Madison \{has stopped / frowns on\} drinking and she used to enjoy vodka, then Joshua will invite her to his group

20. If Abigail \{has stopped / frowns on\} doing yoga and she used to practice Jivamukti yoga, then Matthew will interview her for his story

\footnotetext{
22 We delibarately chose the past tense was hoping that, as that seemed most natural to us for the sentence as a whole.
} 
21. If Olivia \{has stopped / frowns on going to the gym and she used to frequent the gym on campus, then Ethan will ask her to train with him

22. If Isabella \{has stopped / frowns on\} drinking coffee and she used to drink espresso, then Andrew will suggest that she order tea

23. If Hannah \{has stopped / frowns on \} skipping classes and she used to skip Physical Education, then Daniel will not report her to the principal

24. If Samantha \{has stopped / frowns on\} travelling to Italy and she used to go to Rome, then Anthony will offer to take her on his next trip to Spain

25. If Ava \{continues / enjoys visiting museums and she has been frequenting science museums, then Christopher will have a lot to talk to her about

26. If Ashley \{continues / enjoys\} watching sports and she has been watching baseball matches, then Joseph will talk to her about the World Series

27. If Sophia \{continues / enjoys\} going out to eat and she has been eating at expensive restaurants, then William will get her a Wine and Dine magazine subscription

28. If Elizabeth \{continues / enjoys \} eating meat and she has been eating red meat, then Alexander will not want to go out to eat with her

29. If Alexis \{continues / enjoys\} failing exams and she has been flunking end-of-the-year exams, then Ryan will not let her study abroad

30. If Grace \{continues / enjoys \} hosting parties and she has been throwing massive parties, then David will go live somewhere else

31. If Sarah \{continues / enjoys\} adopting pets and she has been adopting cats, then Nicholas will suggest she get a hamster

32. If Alyssa \{continues / enjoys\} working in academia and she has been working for Harvard, then Tyler will nominate her for the research committee

\subsection{Details of results and statistical analysis}

See Tables 2 and 3 and Figs. 6 and 7.

Table 2 Estimated coeffecients, standard errors, Wald's $z$, and $p$ values from logistic mixed effect model of the form (Answer $==$ "Yes") Ps * order + (1+ Ps + order I subject $)+(1 \mid$ item $)$, with centered predictors

\begin{tabular}{lllll}
\hline Interaction analysis ... & $\beta$ & $S E$ & $z$ & $p$ \\
\hline Interaction & 0.98 & 0.28 & 3.56 & $<.001$ \\
Main Effect of Ps vs. No-Ps & -1.41 & 0.16 & -8.86 & $<.001$ \\
Main Effect of First vs. Second & -1.25 & 0.21 & -6.06 & $<.001$
\end{tabular}

Significant $\mathrm{p}$-values $(\mathrm{p}<0.05)$ are reported in bold

Table 3 Estimated coeffecients, standard errors, Wald's $z$, and $p$ values from logistic mixed effect model of the form (Answer $==$ "Yes") $\sim$ Ps * order $+(1+$ Ps + order I subject $)+(1$ I item $)$, with treatment coded predictors and baselines adjusted for assessing respective simple effects

\begin{tabular}{llllc}
\hline Simple effect analysis ... & $\beta$ & $S E$ & $z$ & $p$ \\
\hline Conj-Ps-First vs. Conj-Ps-Second & -1.72 & 0.28 & -6.24 & $<.001$ \\
Conj-No-Ps-First vs. Conj-No-Ps-Second & -0.64 & 0.24 & -2.66 & $<.01$ \\
Conj-Ps-First vs. Conj-No-Ps-First & -1.89 & 0.25 & -7.71 & $<.001$ \\
Conj-Ps-Second vs. Conj-No-Ps-Second & -0.82 & 0.2 & -4.07 & $<.001$
\end{tabular}

Significant $\mathrm{p}$-values $(\mathrm{p}<0.05)$ are reported in bold 


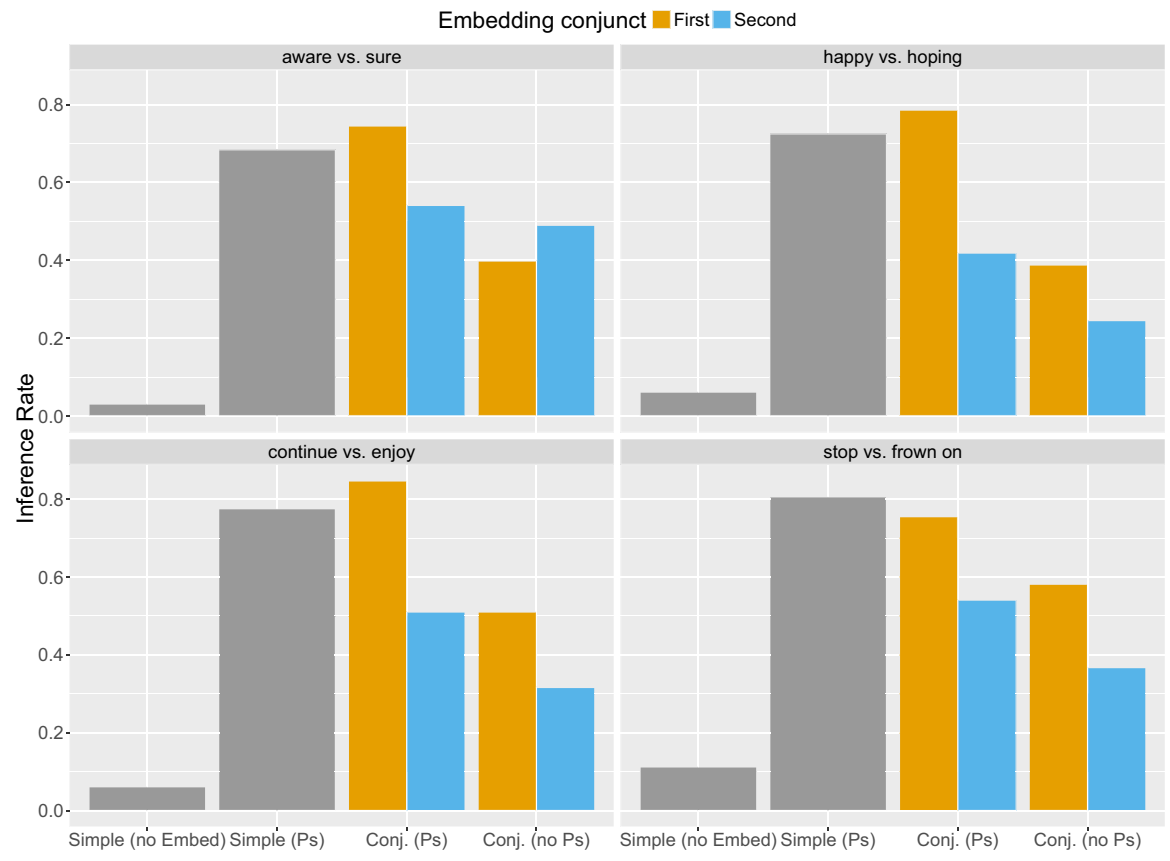

Fig. 6 Mean inference rates of $p$ per condition by trigger and No-Ps control in Experiment 2

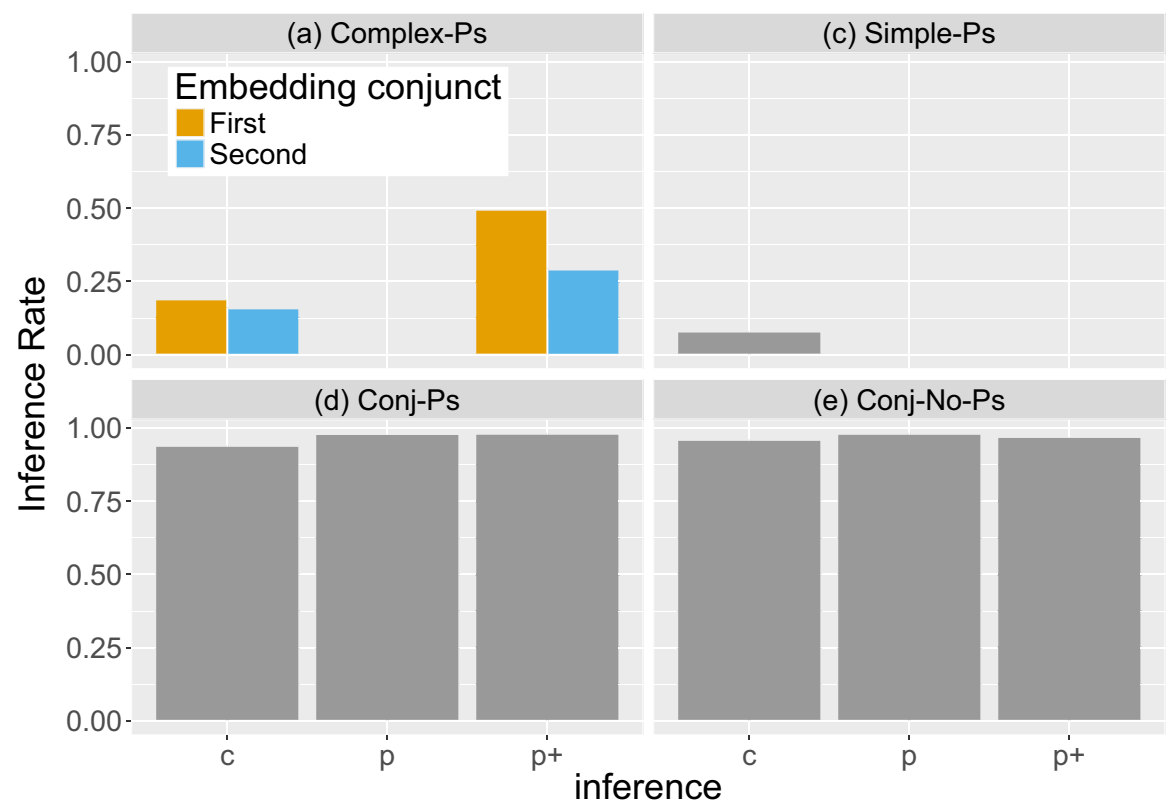

Fig. 7 Mean inference rates for fillers by inference type and conjunct order (where applicable) 


\section{Experiment 3 details}

\subsection{Experimental stimuli}

1. a. Jacob has been traveling a lot, and he's in France this week. If Emily is happy that Jacob is in France and he is in Paris, then she will call him soon.

Support-Conj-Ps-First

b. Jacob has been traveling a lot, and he's in France this week. If Jacob is in Paris and Emily is happy that he is in France, then she will call him soon.

Support-Conj-Ps-Second

c. Jacob has been traveling a lot, and he's in France this week. If Emily is happy that Jacob is in France, then she will call him soon.

Support-Simple-Ps

d. Jacob has been traveling a lot, but I'm not sure where he is this week. If Emily is happy that Jacob is in France and he is in Paris, then she will call him soon.

Expl-Ign-Conj-Ps-First

e. Jacob has been traveling a lot, but I'm not sure where he is this week. If Jacob is in Paris and Emily is happy that he is in France, then she will call him soon.

Expl-Ign-Conj-Ps-Second

f. Jacob has been traveling a lot, but I'm not sure where he is this week. If Emily is happy that Jacob is in France, then she will call him soon.

Expl-Ign-Simple-Ps

g. Jacob has been traveling a lot, and he's in France this week. If Emily was hoping that Jacob is in France and he is in Paris, then she will call him soon.

Support-Conj-No-Ps-First

h. Jacob has been traveling a lot, and he's in France this week. If Jacob is in Paris and Emily was hoping that he is in France, then she will call him soon.

Support-Conj-No-Ps-Second

i. Jacob has been traveling a lot, and he's in France this week. If Emily was hoping that Jacob is in France, then she will call him soon.

Support-Simple-No-Ps

j. Jacob has been traveling a lot, but I'm not sure where he is this week. If Emily was hoping that Jacob is in France and he is in Paris, then she will call him soon.

Expl-Ign-Conj-No-Ps-First

$\mathrm{k}$. Jacob has been traveling a lot, but I'm not sure where he is this week. If Jacob is in Paris and Emily was hoping that he is in France, then she will call him soon.

Expl-Ign-Conj-No-Ps-Second

1. Jacob has been traveling a lot, but I'm not sure where he is this week. If Emily was hoping that Jacob is in France, then she will call him soon.

Expl-Ign-Simple-No-Ps

2. Michael has moved around a lot, and \{currently lives in Japan / I'm not sure where he lives at the moment\}. If Emma \{is happy / was hoping\} that Michael lives in Japan and he lives in Tokyo, then she will go visit him

3. Joshua has many hobbies, \{and has been playing an instrument for a while / but I don't know whether he plays an instrument\}. If Madison \{is happy / was hoping\} that Joshua plays an instrument and he plays the piano, then she will invite him to the party.

4. Matthew has been traveling in Europe, \}and his last stay was in Germany / but I'm not sure whether he went to Germany\}. If Abigail \{is happy / was hoping that \} that Matthew travelled to Germany and he travelled to Berlin, then she will ask him to write a post on her blog

5. Daniel has opened a gift shop, \{and also sells flowers / but I don't know whether he sells flowers\}. If Hannah \{is happy / was hoping\} that Daniel sells flowers and he sells roses, then she will go check out his store

6. Anthony is well-trained in arts and crafts, \}and he also designs clothes / but I don't know whether he designs clothes\}. If Samantha \{is happy / was hoping\} that Anthony designs clothes and he designs shirts, then she will ask him to work for her 
7. Christopher has various nervous habits, \{and he smokes cigarettes / but I don't know whether he smokes\}. If Ava is \{aware/ sure\} that Christopher smokes cigarettes and he smokes Marlboros, then she will tell him about the recent class action suit

8. Joseph is a big theater fan, \{and he also likes music / but I don't know whether he likes music $\}$. If Ashley is \{aware / sure \} that Joseph likes music and he likes classical music, then she will give him a biography of Beethoven

9. William is a big fan of electronic gadgets, \{and he also likes musical instruments / but I don't know whether he likes musical instruments\}. If Sophia is \{aware / sure $\}$ that William likes musical instruments and he likes violins, then she will ask him to visit the musem of musical instruments with her

10. Ryan loves riding motorcycles, $\{$ but he also drives / but I don't know whether he drives $\}$. If Alexis is \{aware / sure\} that Ryan drives and he drives a Toyota, then she will get a ride from him

11. David loves going to coffee shops, \{and he also likes to eat out / but I don't know whether he likes to eat out\}. If Grace is \{aware / sure\} that David likes to eat out and he likes to eat at Mexican restaurants, then she will take him for Mexican

12. Tyler enjoys gardening, \{and he also likes animals / but I don't know whether he likes animals\}. If Alyssa is \{aware / sure that Tyler likes animals and he likes dogs, then she will ask him if he knows anyone that could walk her dog

13. Emily used to enjoy boardgames, \{and she also loved playing with toys when she was little / but I don't know whether she ever played with toys\}. If Emily \{has stopped / now frowns on playing with toys and she used to play with toy cars, then Jacob will buy her racing video games for her birthday

14. Emma used to read a lot of poetry, \{and she also used to read a novel a week / but I don't know whether she ever read any novels\}. If Emma \{has stopped / now frowns on\} reading novels and she used to enjoy sci-fi novels, then Michael will take her to a sci-fi movie

15. Abigail always was involved in a lot of sports, \{and she used to do yoga, too / but I don't know whether she ever did any yoga\}. If Abigail \{has stopped / now frowns on\} doing yoga and she used to practice Jivamukti yoga, then Matthew will interview her for his story

16. Isabella has always liked tea, \{and she used to drink coffee, too / but I don't know whether she's ever had coffee\}. If Isabella \{has stopped / now frowns on \} drinking coffee and she used to drink a lot of coffee, then Andrew will suggest that she order tea

17. Hannah never was the most diligent student, \{and she used to skip classes / but I don't know whether she ever skipped any classes\}. If Hannah \{has stopped / now frowns on \} skipping classes and she used to skip French, then Daniel will not report her to the principal

18. Samantha is quite the globe trotter, \{and she used to go to Italy quite regularly / but I don't know whether she's ever been to Italy\}. If Samantha \{has stopped / now frowns on\} travelling to Italy and she used to go to Rome, then Anthony will offer to take her on his next trip to Spain

19. Ava always liked going to churches, \{and she's also visited many museums / but I don't know whether she has ever been to a museum\}. If Ava \{continues / enjoys \} visiting museums and she has been frequenting science museums, then Christopher will have a lot to talk to her about

20. Ashley always loved watching sitcoms, \{and she also has been watching sports quite a bit / but I don't know whether she's ever watched any sports\}. If Ashley \{continues / enjoys\} watching sports and she has been watching baseball, then Joseph will invite her to watch next year's World Series with him

21. Sophia loves cooking exotic food, \{and she used to go out to eat a lot / but I don't know whether she's ever gone out to eat\}. If Sophia \{continues / enjoys\} going out to eat and she has been eating at expensive restaurants, then William will get her a Wine and Dine magazine subscription

22. Elizabeth is a fish conoisseur, \{and she also frequently eats meat / but I don't know whether she's ever had meat\}. If Elizabeth \{continues / enjoys\} eating meat and she has been eating red meat, then Alexander will not want to go out to eat with her

23. Alexis is not a good student, \{and recently she's been failing exams / but I don't know whether she's ever failed an exam\}. If Alexis \{continues / enjoys\} failing exams and she has been flunking end-of-the-year exams, then Ryan will suggest that she work with the counselling center 
24. Sarah loves animals, \{and she has adopted pets quite often / but I don't know whether she's ever adopted a pet\}. If Sarah \{continues / enjoys adopting pets and she has been adopting cats, then Nicholas will suggest she move out

\section{Fillers}

a. Non-Presuppositional fillers with simple antecedent (16 total, with contexts counterbalanced within item across participant groups):

i. Unacceptable Context (parallel to Support):

Ethan is planning a trip, and he'll go to England first.

ii. Acceptable Context (parallel to Expl-Ign):

Ethan is planning a trip, but I don't know whether he's coming to England.

If Ethan isn't coming to England, then Olivia will invite somebody else for dinner

b. Presuppositional Conjunction fillers (16 total, varying triggers, 4 for each trigger except for continue, which was replaced by still in 3 out of 4 items to make the sentences more natural; contexts were counterbalanced within item across participant groups):

i. Acceptable Context (parallel to Support):

Anna recently got married and is expecting a baby.

ii. Uncceptable Context (parallel to Expl-Ign):

Anna recently got married, but I don't know whether she's going to have kids.

Gerald is happy that Anna is pregnant and he will buy her a present

\subsection{Details of results and statistical analysis}

See Tables 4, 5, 6, 7 and Figs. 8 and 9.

Table 4 Estimated coeffecients, standard errors, and $t$ values from linear mixed effect model of the form Answer Order * Embedding Type $*$ Context $+(1$ | Subject $)+(1+$ Embedding Type * Context I Item), with treatment coding and Conj-Ps-First-Expl-Ign as baseline

\begin{tabular}{lrlr}
\hline 3-Way interaction analysis ... & \multicolumn{1}{l}{$\beta$} & \multicolumn{1}{l}{$S E$} & \multicolumn{1}{c}{$t$} \\
\hline Intercept & 2.09 & 0.23 & 8.96 \\
Second & 1.57 & 0.15 & 10.31 \\
Simple & -0.14 & 0.15 & -0.94 \\
No-Ps & 1.25 & 0.29 & 4.33 \\
Support & 1.66 & 0.28 & 5.86 \\
Second:No-Ps & 1.28 & 0.22 & -5.80 \\
Simple:No-Ps & 0.44 & 0.22 & 2.01 \\
Second:Context & -1.31 & 0.22 & -6.06 \\
Simple:Context & 0.80 & 0.22 & 3.67 \\
No-Ps:Context & -1.31 & 0.39 & -3.39 \\
Second:No-Ps:Context & 0.96 & 0.31 & 3.09 \\
Simple:No-Ps:Context & -0.98 & 0.31 & -3.16 \\
\hline
\end{tabular}


Table 5 Estimated coeffecients, standard errors, and $t$ values from logistic mixed effect model of the form (Answer $==$ "Yes") $\sim$ Embedding Type * Order $+(1+$ Embedding Type I Subject $)+(1+$ Embedding Type * Order I Item) with centered predictors, for conjunctive stimuli in the Expl-Ign conditions. Model comparison for the interaction confirmed its significance, with $\chi^{2}=11.56$, and $p<.001$

\begin{tabular}{lccr}
\hline Order * Embedding Type Interaction ... & $\beta$ & SE & \multicolumn{1}{c}{$t$} \\
\hline Main effect of Order & 0.96 & 0.18 & 5.34 \\
Main effect of Embedding Type & 0.61 & 0.27 & 2.28 \\
Interaction & -1.27 & 0.35 & -3.59 \\
\hline
\end{tabular}

Table 6 Estimated coeffecients, standard errors, and $t$ values from logistic mixed effect model of the form (Answer $==$ "Yes") $\sim$ Context * Order $+(1+$ Order I Subject $)+(1+$ Context * Order I Item $)$ with centered predictors, for conjunctive stimuli in the $P s$ conditions. Model comparison for the interaction confirmed its significance, with $\chi^{2}=15.53$, and $p<.001$

\begin{tabular}{lcrr}
\hline Order * Context Interaction ... & $\beta$ & $S E$ & $t$ \\
\hline Main effect of Order & 0.92 & 0.17 & 5.43 \\
Main effect of Context & 1.00 & 0.25 & 4.09 \\
Interaction & -1.30 & 0.31 & -4.21
\end{tabular}

Table 7 Estimated coeffecients, standard errors, and $t$ values from logistic mixed effect model of the form (Answer $==$ "Yes") $\sim$ Embedding Type * Context $+(1$ । Subject $)+(1+$ Embedding Type * Context I Item), with centered predictors for conjunctive stimuli in the Expl-Ign conditions. Model comparison for the interaction confirmed its significance, with $\chi^{2}=10.04$, and $p<.01$

\begin{tabular}{llll}
\hline Context * Embedding Type Interaction ... & $\beta$ & $S E$ & $t$ \\
\hline Main effect of Context & 1.01 & 0.20 & 5.09 \\
Main effect of Embedding Type & 0.59 & 0.23 & 2.55 \\
Interaction & -1.32 & 0.41 & -3.23 \\
\hline
\end{tabular}




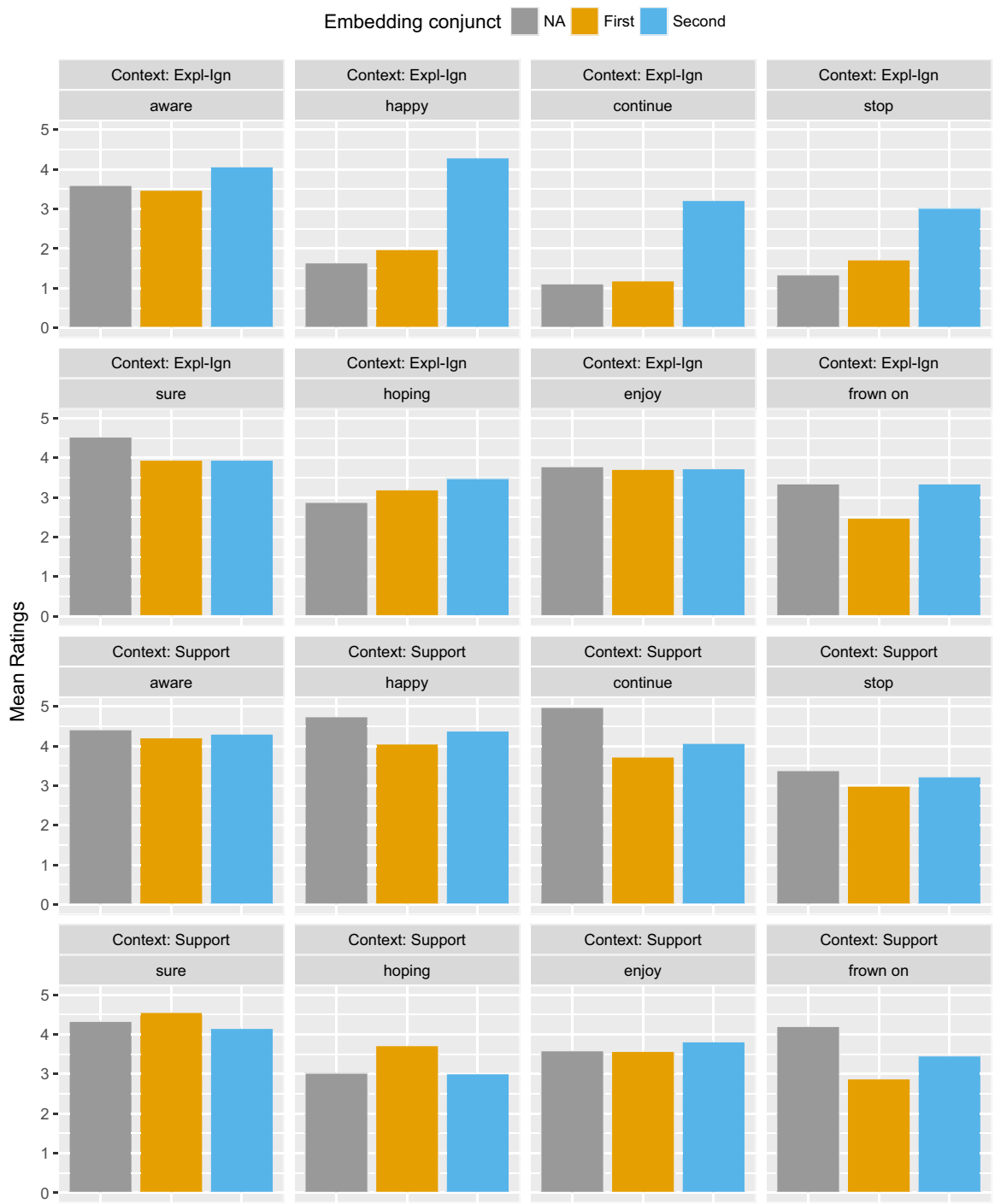

Fig. 8 Mean acceptability ratings per context and order by trigger in Experiment 3 


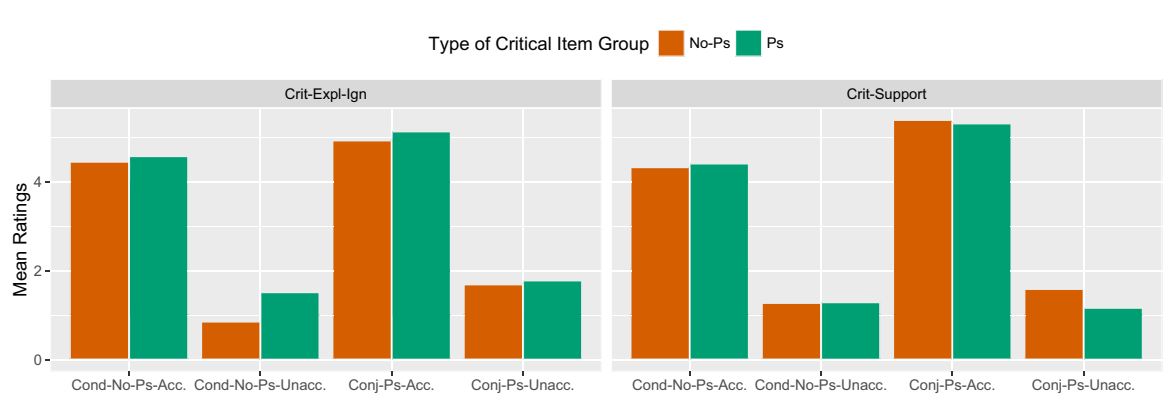

Fig. 9 Mean acceptability ratings for fillers by type and between-subject factor groups (context and embedding type for critical items)

\section{References}

Chemla, E. (2008). Similarity: Towards a unified account of scalar implicatures, free choice permission and presupposition projection. Manuscript, Ecole Normale Supérieure, Paris and MIT. http://www. emmanuel.chemla.free.fr/Material/Chemla-SIandPres.pdf.

Chemla, E., \& Schlenker, P. (2012). Incremental versus symmetric accounts of presupposition projection: An experimental approach. Natural Language Semantics, 20(2), 177-226. https://doi.org/10.1007/ s11050-012-9080-7.

Chierchia, G. (2009). On the explanatory power of dynamic semantics. Handout from talk at Sinn und Bedeutung 14.

Chierchia, G., \& McConnell-Ginet, S. (1990). Meaning and grammar. Cambridge, MA: MIT Press.

Chung, W. (2017). An evaluation-sensitive model for local context computation. (Unpublished manuscript NYU).

Djärv, K., \& Bacovcin, H. A. (2017). Prosodic effects on factive presupposition projection. In D. Burgdorf, J. Collard, S. Maspong, \& B. Stefánsdóttir (Eds.), Proceedings of SALT 27 (pp. 116-133). https://doi. org/10.3765/salt.v27i0.4134.

Fox, D. (2008). Two short notes on Schlenker's theory of presupposition projection. Theoretical Linguistics, 34(3), 237-252.

Gazdar, G. (1979). Pragmatics: Implicature, presupposition and logical form. New York: Academic Press.

George, B. R. (2008). Presupposition repairs: A static, trivalent approach to predicting projection. University of California, Los Angeles MA thesis. http://www.semanticsarchive.net/Archive/2ZiYmEyN/ brgeorge_ma.pdf.

Geurts, B., \& Pouscoulous, N. (2009). Embedded implicatures?!? Semantics \& Pragmatics, 2(4), 1-34.

Grice, P. (1989). Studies in the way of words. Cambridge, MA: Harvard University Press.

Heim, I. (1983). On the projection problem for presuppositions. In M. Barlow, D. P. Flickinger, \& N. Wiegand (Eds.), Proceedings of the 2nd West Coast Conference on Formal Linguistics (pp. 114125). Stanford, CA: Stanford University Press. Reprinted in P. Portner, \& B. H. Partee (Eds.), Formal semantics: The essential readings (pp. 223-248). New York: Wiley-Blackwell, 2002. https://doi.org/ 10.1002/9780470758335.ch10.

Hirsch, A., \& Hackl, M. (2014). Incremental presupposition evaluation in disjunction. In J. Iyer, \& L. Kusmer (Eds.), Proceedings of the 44th annual meeting of the North East Linguistic Society (Vol. 1, pp. 177-190). Amherst, MA: GLSA.

Hirsch, A., Zehr, J., \& Schwarz, F. (2018). Presupposition projection from disjunction in online processing. In R. Truswell, C. Cummins, C. Heycock, B. Rabern, \& H. Rohde (Eds.), Proceedings of Sinn und Bedeutung 21 (Vol. 1, pp. 547-566). https://semanticsarchive.net/Archive/DRjNjViN/SuB21.pdf.

Ingason, A. K. (2016). Context updates are hierarchical. Glossa, 1(1), 1-9.

Karttunen, L. (1973). Presuppositions of compound sentences. Linguistic Inquiry, 4(2), 167-193.

Karttunen, L. (1974). Presupposition and linguistic context. Theoretical Linguistics, 1(1-3), 181-194. https://doi.org/10.1515/thli.1974.1.1-3.181.

Karttunen, L., \& Peters, S. (1979). Conventional implicature. Syntax and Semantics, 11, 1-56. 
Katzir, R., \& Singh, R. (2013). Hurford disjunctions: Embedded exhaustification and structural economy. In U. Etxeberria, A. Fălăuş, A. Irurtzun \& B. Leferman (Eds.), Proceedings of Sinn und Bedeutung 18 (pp. 201-216). https://semanticsarchive.net/sub2013/SeparateArticles/Katzir\&Singh.pdf.

Mandelkern, M. (2016). A note on the architecture of presupposition. Semantics \& Pragmatics, 9(13), 1-24. https://doi.org/10.3765/sp.9.13.

Mandelkern, M. (2019). Bounded modality. The Philosophical Review, 128(1), 1-61. https://doi.org/10. 1215/00318108-7213001.

Mandelkern, M., \& Romoli, J. (2017). Parsing and presupposition in the calculation of local contexts. Semantics \& Pragmatics, 10(17). https://doi.org/10.3765/sp.10.7.

Mayr, C., \& Romoli, J. (2016). A puzzle for theories of redundancy: Exhaustification, incrementality, and the notion of local context. Semantics \& Pragmatics, 9(7), 1-48. https://doi.org/10.3765/sp.9.7.

Romoli, J. (2012). A solution (or two) to Soames' problem: Presuppositions, conditionals and exhaustification. International Review of Pragmatics, 4(2), 153-184.

Romoli, J., \& Mandelkern, M. (2018). Hierarchical structure and local contexts. In R. Truswell, C. Cummins, C. Heycock, B. Rabern \& H. Rohde (Eds.), Proceedings of Sinn und Bedeutung 21 (pp. 1017-1034). https://semanticsarchive.net/Archive/DRjNjViN/SuB21.pdf.

Rothschild, D. (2008). Presupposition projection and logical equivalence. Philosophical Perspectives, 22 , 473-497.

Rothschild, D. (2011/2015). Explaining presupposition projection with dynamic semantics. Semantics \& Pragmatics 4(3), 1-43. https://doi.org/10.3765/sp.4.3.

Schlenker, P. (2008a). Be articulate: A pragmatic theory of presupposition projection. Theoretical Linguistics, 34(3), 157-212. https://doi.org/10.1515/THLI.2008.013.

Schlenker, P. (2008b). Presupposition projection: Explanatory strategies. Theoretical Linguistics, 38(3), 287-316. https://doi.org/10.1515/THLI.2008.021.

Schlenker, P. (2009). Local contexts. Semantics \& Pragmatics, 2(3), 1-78. https://doi.org/10.3765/sp.2.3.

Schwarz, F. (2015). Symmetry and incrementality in conditionals. In F. Schwarz (Ed.), Experimental perspectives on presuppositions (pp. 195-213). Cham: Springer.

Soames, S. (1979). A projection problem for speaker presuppositions. Linguistic Inquiry, 10(4), 623-666.

Stalnaker, R. (1974). Pragmatic presuppositions. In M. K. Munitz \& P. Unger (Eds.), Semantics and philosophy (pp. 197-213). New York: New York University Press.

Stalnaker, R. (1978). Assertion. In P. Cole (Ed.), Syntax and Semantics (Vol. 9, pp. 315-322). New York: Academic Press.

Tonhauser, J. (2016). Prosodic cues to presupposition projection. In M. Moroney, C.-R. Little, J. Collard, \& D. Burgdorf (Eds.), Proceedings of SALT 26 (pp. 934-960). https://doi.org/10.3765/salt.v26i0.3788.

Tonhauser, J., Beaver, D. I., \& Degen, J. (2018). How projective is projective content? Gradience in projectivity and at-issueness. Journal of Semantics, 35, 495-542.

von Fintel, K. (2008). What is presupposition accommodation, again? Philosophical Perspectives, 22(1), $137-170$.

Publisher's Note Springer Nature remains neutral with regard to jurisdictional claims in published maps and institutional affiliations. 